\title{
" متطلبات تطبيق هندرة الجامعات السعودية في ضوء تحديات العصر الرقمي"
}

\section{د. دهب نايف الثمري}

$$
\begin{aligned}
& \text { أستاذ الإدارة التربوية المشارك دلك } \\
& \text { قسم التربية - كلية التربية - جامعة حائل التل }
\end{aligned}
$$

مستخلص. تهدف هذه الدراسة إلى دراسة متطلبات تطبيق هندرة الجامعات السعودية في ضوء تحديات العصر

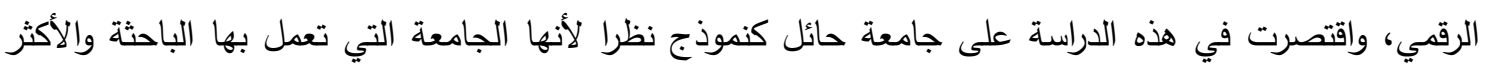

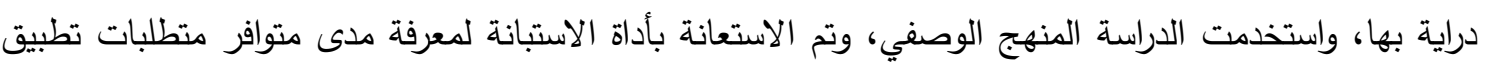

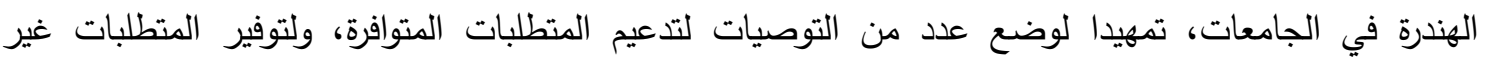

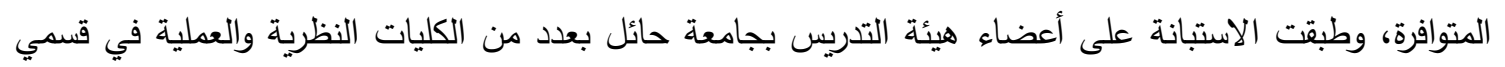

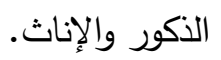
وأسفرت نتائج الدراسة عن تفوق نسبيا محور متطلبات إعادة هندرة العمليات الأكاديمية على محور متطلبات إعادة

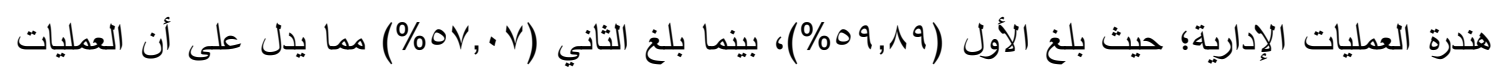

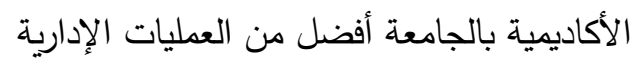
وانتهت الدراسة بوضع عدد من التوصيات التي من شأنها تدعيم متطلبات الهندرة المتوافرة، وتوفير متطلبات الهندرة غير المتوافرة على المحورين الإداري والأكاديمي. الكلمات المفتاحية: الهندرة - العصر الرقمي - الجامعات السعودية الإدادية

النصف الثاني من القرن العشرين تطورًا تكنولوجيًا

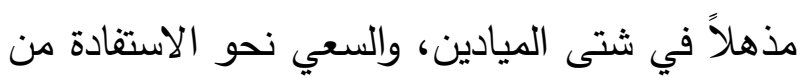

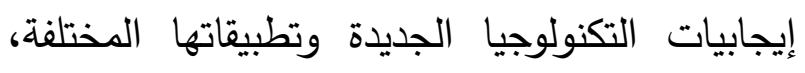
وظهور قضية إتاحة المعرفة وارتباطها بالقدرة على وتطئي الرقمنة، وهى المرحلة الدقيقة والمهمة التي بلغتها

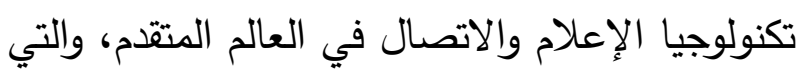
صبغت هذا المجتمع وأثرت فيه حتى أصبح يعبر

\section{المقدمة}

بدأ إرهاصات العصر الرقمي منذ فجر التاريخ، على المقاءه

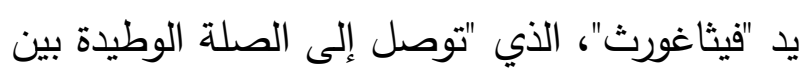

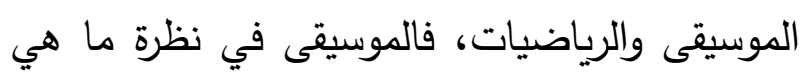

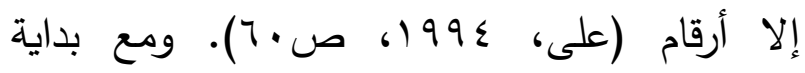
النهضة التي قامت على أكتاف الثورة الصناعية، حدث تطور في مختلف مجالات الحياة، وشهد 
العصر الرقمي؛ حيث أصبحت تقنياته تمثل العمود

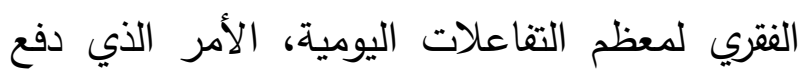
معظم الدول إلى تبني نموذج الحكومات الذكية

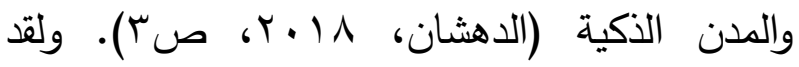
تحولت المعلومات من الثكل الورقي إلى الثكل الإلكتروني، واتسم العصر بالتواصل عبر البيئات

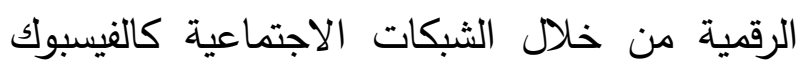
وتويتر وغيرها (Haris, 2016, pp.13). وتسعى مؤسسات التعليم العالي في المملكة العربية السعودية في الوقت الحالي إلى إحداث تغييرات جوهرية وتحديث بنية العمليات والمعلومات لديها لاعم وزيادة قدرتها على المنافسة والبقاء وذلك ونكات وليه لمواجهة العديد من التحديات المتعلقة بتطوير أدائها واستغلاله الاستغلال الأمثل بما يحقق الكفاءة والفاعلية في ظل بيئة تتسم بالمنافسة والتسارع العلمي والتكنولوجي. وتتمثل هذه التحديات في ضعف توظيف علاقة الاستثمار بين الإمكانات والموارد البشرية والمادية وبين إعادة هندسة العمليات الإدارية، وهي بذلك تشكل عقبة أمام الدور الإستراتيجي الذي تلعبه هذه السياسات في انغماس كافة منسوبي الجامعة ومشاركتهم في تحقيق أهداف الجامعة. وفي ظل تلك الظروف أصبحت كفاية العمليات الإدارية تثير قلقا كبيرا للكثير من المؤسسات خلال العقود الأخيرة خاصة المؤسسات التعليمية، وتبعا لذلك طورت العديد من الطرائق
عنه بالعصر الرقمي؛ فالرقمنة أحدثت ثورة حقيقية،

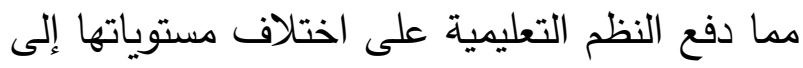
الاستفادة من هذا التطور الهائل في التكنولوجيا الرقمية. وصار ينظر إلى الثورة التقنية والمعلوماتية باعتبارها ثورة تربوية على الممارسات التقليدية

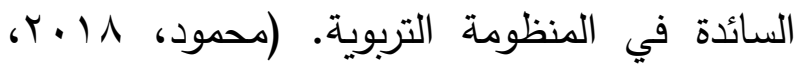

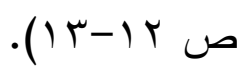
ولقد ظهر مفهوم التعلم الرقمي في العقود الأربعة

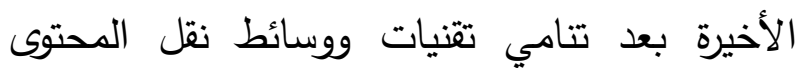
التعليمي؛ مما دعا المختصين إلى الاستفادة من هذه لهي التقنيات في تسهيل نقل التعلم إلى الطلاب، والاستفادة منها في رفع كفاءة التعلم والمهارات الشخصية، والتركيز على المتعلم باعتباره محور العملية التعليمية بعد أن كان متلقي. (الإقبالي،

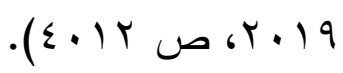
وتتطور التكنولوجيا الرقمية بشكل يدفع إلى الابتكار

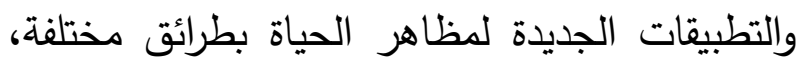
وتتسع الفرص والتطلعات التي ترتبط بالرقمنة. ولقد أحدث ذلك التطور تطلعات لمزيد من المهارات الجديدة، ومن ثم بات على الجميع مواصلة تطوير

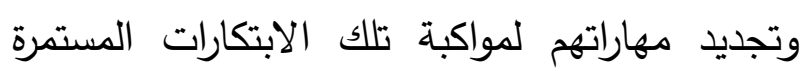
والمتلاحقة في العالم الرقمي في شتى مناحي الحياة؛ كحجز مواعيد الطائرات، وزيارة طبيب، والتعاملات

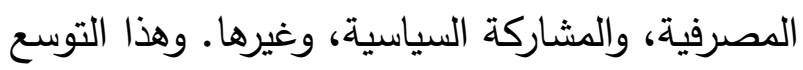
في تطبيقات الرقمنة، دفع البعض إلى القول بأننا

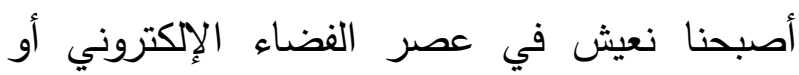


مشكلة الدراسة: - مئ

لقد أشار تقرير توجهات التعليم العالي في 9 1 • بم

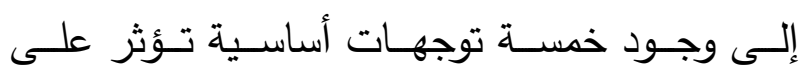
استراتيجايت تكنولوجيا المعلومات في التعليم العالي ومـن أهمهــا؛ المخــاطر المتزايــدة المتعلقــة بـأمن المعلومات، وضرورة التركيز على الطالب، وضرورة صـنـع القـرارات المبنيـة علـى المعلومـات، وسـرعة التطـور التكنولـوجي وتعقيداتـه، والتــأثير الإيجـابي

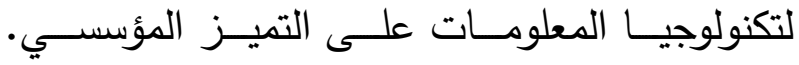
(Brooks \& McCormack, 2019) ولقد تزايدت التحديات العالميـة التي تؤكد على أهميـة وضـرورة هندرة مؤسسـات التعليم العـالي، ومنهـا على سـبيل المثال؛ القدرة على تطوير الأداء البشري للمعلمين والطـلاب على حد سـواء، ضـعف النتـائج المحقــة مقارنـة بالنتـائج المخطط لهـا، (Ali,2016) وكذلك التركيز على رضـا العمـلاء واحتياجـاتهم، و خفض الوقت والتكلفة ورفع الجودة، والرغبة الملحة لتحسين الكفاءة والفعالية وهو حافز قوي للشـروع في عملية الهندرة (Doyle, 2004, 20 ) وتغير الاحتياجات التعليمية بسبب الابتكارات، وسرعة تدفق المعلومات والمعرفة وتغير المهن، متطلبات فرص التعليم البديلة التي تتفق أكثر مـع الحياة والعصر والمستويات لكل فرد (Sprawls, 2013) وتري الباحثة أنه على الرغم من أنه ظهرت في السنوات الأخيرة العديد من الدراسات العلمية في مجال تطبيق عملية إعادة هندسة العمليات الإدارية
والأدوات لتحسين وتطوير العمليات التظيمية .(Chain \& Spedding 2003, 674) وفي ذات السياق قد أشار التل إلى أن التعليم العالي يعاني من التصلب والجمود والثكلية في هياكله وبناه التظيمية وبرامجه ومناهجه المعتمدة وانعدام المواءمة بين نواتج التعليم واحتياجات خطط التتمية، واختلال التوازن بين النمو الكمي وبين نوعية التعليم وجودته ، وقد تجلت هذه الظاهرة لدي المقارنة بين المهارات التي يكتسبها الخريجون ومتطلبات سوق العمل وكذلك عدم التسيق بين سياسات التدريب والتعليم وبين حاجات سوق العمل في المؤسسات

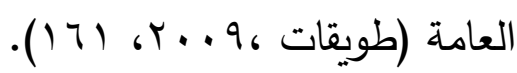
وفي المقابل تعد الجامعات مؤسسات أكاديمية بحثية ترتبط في تحقيق أهدافها ارتباطاً وثيقاً بالبيئة والمجتمع المحيط بها وبناء على ذلك فهي تحتاج إلى التطوير المستمر في أنظمتها الإدارية التي تتبعها وبما يتناسب مع تطور البيئة والمجتمع المحيط ، وفي ذات السياق قد شهدت جامعة حائل خلال السنوات الأخيرة تطورا ملموسا سواء من حيث نوعية وجودة البرامج الأكاديمية التي تقدمها أو من حيث عدد المنسوبين لها من أعضاء هيئة التدريس وإدارين وطلاب وطالبات أو من حيث التوسع الجغرافي لها والذي ضم العديد دن فروع الجامعة في عديد من المناطق والمحافظات المحيطة بحائل. 
• ما أهم متطلبات تطبيق الندرة التي يوصى بها بجامعة حائل لتطبيق عملية الهندرة؟ أهمية الدراسة: تكمن أهمية الدراسة في مواكبة التطورات العالمية التي تفرض نفسها على المجتمعات بشكل عام والجامعات بشكل خاص، ويأتي في مقدمة تلك لكرات التطورات التحديات التي يفرضها العصر الرقمي، مما يستوجب إعادة هندرة الجامعات السعودية بما لئال يتواكب مع تلك التحديات. وحيث إن الهندرة من العمليات الكبرى التي تأخذ العديد من المراحل، فإن هذا البحث يقوم بدراسة أهم

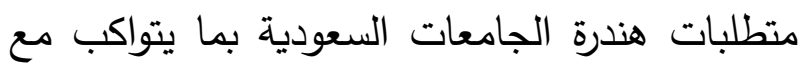

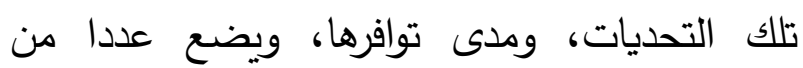
التوصيات في هذا الثأن لتوفير تلك المتطلبات حتى تونى تكون مستعدة لعمليات الهندرة مستقبلا. أهداف الدراسة:

تسعي هذه الدراسة لتحقيق الاهداف التالية: • التعريف بمفهوم الهندرة وخصائصها ومبادئها.

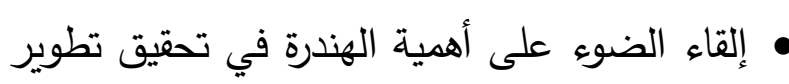
ملموس في كفاءة العمليات الإدارية والأكاديمية. • معرفة مدى توافر متطلبات هندرة العمليات الإدارية والأكاديمية الحالية بالجامعات السعودية (جامعة حائل) من وجهة نظر أفراد البحث (أعضاء هيئة التدريس).

عرض بعض تجارب الدول العالمية لمعرفة متطبات تطبيق عملية الهندرة في جامعتها.
في الجامعات والمؤسسات العلمية لتطوير العمل الإداري بها بما يشجع على الإبداع والتجديد والابتكار والمساعدة في حل العديد من المشكلات الإدارية إلا أنه مازالت الحاجة إلى ضراعلى فروة تدعيم تطبيق هذا المجال في التعليم والبحث العلمي بما يتناسب مع المفهوم الحديث للبحث العلمي والذي في يتطلب من الجامعات والمؤسسات البحثية القيام بالعديد من المهام والأنشطة المتعددة والمتنوعة لمواجهة تحديات العصر الحالي. بلمنيل وحتى تتمكن الجامعات بصفة عامة وجامعة حائل بصفة خاصة من معايشة تحديات العصر، والقيام بمهامها بجودة عالية، ووقت قياسي بأقل مجهود وأقل التكاليف، فأن عليها أن تخوض عملية تغيير شامل وجذري للعمليات الإدارية بما يضمن تحقيق قفزة نوعية للإدارة في مستويات الأداء وبذلك يمكن صياغة مشكلة الدراسة الحالية في التساؤل الرئيس

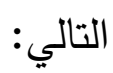
ما متطلبات تطبيق الهندرة في الجامعات السعودية؟ ويتفرع عن هذا السؤال الرئيس الاسئلة الفرعية

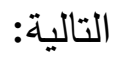
ما أهم متطلبات تطبيق الهندرة في الجامعات من

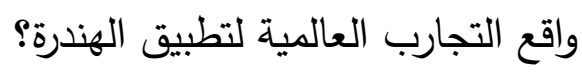

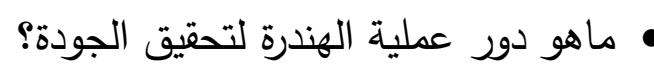
• ما واقع تواجد متطلبات تطبيق الهندرة في جامعة حائل؟ 
• الهندرة Reengineering: تعرّف بأنها" إعادة التّكير بشكل أساسي والعمل على إعادة تصميم عمليّة اتِّاذ القرار التّربوي بشكلٍ جذري، للعمل على إنى إنجاز تحسينات جوهريّة في أداء الاجراءات المناسبة

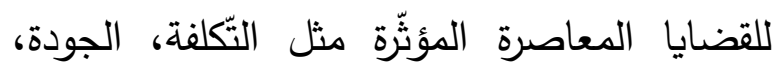
الخدمة، واليّرعة )هامر، مايكل، ستيفن ستانتن، (r...

• العصر الرقمي: يشمل العصر الرقمي جميع الخدمات الرقمية العامة ووسائل التواصل الاجتماعي، ومجتمع الثبكات و وتأثيرات الثورة الصناعية الرابعة على كل من العمل، والعيش، والتعلم، والتواصل، والأداء، والارتباط، إلخ. ويعكس هرنه

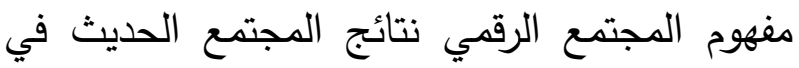
تبني ودمج المعلومات والاتصالات والتتنيات في المنزل والعمل والتعليم والترفيه. وتعيد الابتكارات الرقمية تشكيل المجتمع والاقتصاد والصناعات بحجم Slåtto, T., 2020, ) وسرعة لم يسبق لها مثيل (pp. 17-18 الاطار النظري والدراسات السابقة:

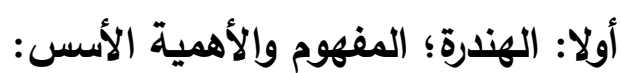
مفهوم الهندرة:

هي كلمة عربية جديدة مركبة من كلمتين هما الهندسة والادارة وهي ترجمة للمصطلح الإنجليزي Business Reengineering هندسة الأعمال أو إعادة هندسة نظم العمل. يرجع

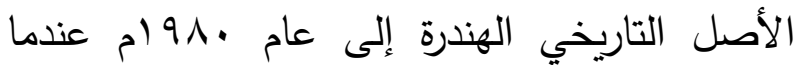

تقديم عدد من التوصيات التي يمكن أن تسهم في توفير متطلبات تطبيق هندرة العمليات الإدارية والأكاديمية في كليات جامعة حائل. حدود الدراسة : تتمثل حدود هذه الدراسة فيما يلي: • الحد الموضوعي: اقتصرت الدراسة على تقديم عدد من التوصيات التي يمكن أن تسهم في توفير

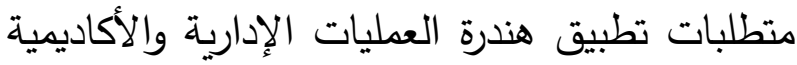
في كليات جامعة حائل في ضوء التوجهات العالمية لمتطلبات تطبيق الجودة وواقع توافر تلك المتطلبات في جامعة حائل. • الحد البشري والدكاني: سوف تقتصر الدراسة على جامعة حائل كدراسة حالة نظرا لأنها الجامعة

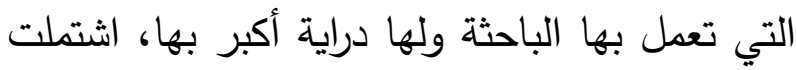
عينة الدراسة من أعضاء هيئة التدريس من الذكور والإناث بمختلف درجاتهم العلمية في الكليات العملية

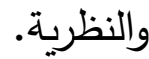
• الحد الزماني: تم جمع البيانات الخاصة بهذه الدراسة خلال الفصل الدراسي الثاني عام جامعي 9r منهج الاراسة: اعتمدت هذه الدراسة على المنهج الوصفي التحليلي والذي يعتمد على جمع البيانات وتبويبها وتحليلها لتنسير النتائج. مصطلحات الدراسة: اشتملت الدراسة على المصطلحات التالية: 
• "اســـتخدام الأدوات والوســـائل للاســـفادة مــن

التكنولوجيا الحديثة لإحداث أفضل مزيـج مدكن لهذه الأدوات والوسـائل للوصـول إلى التغير الجذري في جميع أجزاء المنظمة لأجل تلبية احتياجات العملاء".

(Parker, 1993 : 29)

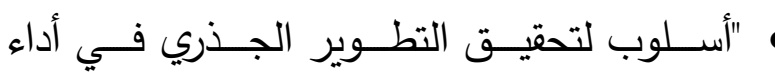

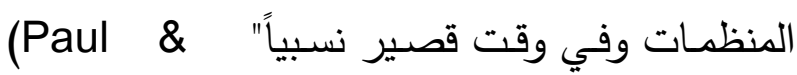

.Cespedes, 1995: 36)

• "إعـــادة تصــــيم ســـريـع وجــــري للعمليـــات

الإستراتيجية لرفع القيمة المضافة لها، وإعادة تصميم

الـنظم والسياسـات والهياكـل التنظيميـة التـي تـدعم

عمليات تحسين سير العمل وإنتاج المؤسسة وتحقيق الغايـات والأهـداف الإسـتراتيجية، وتلبيـة احتياجـات

العملاء". (Fragoso, 2015,383)

أما عن الهندرة في المؤسات التعليمية فلقد نشأ هذا المدخل مع كثرة دعوات التطوير والإصلاح التربوي. (Rottmann, 2017,146) لإعادة هندسة العمليات الإدارية بالمؤسسات لرفع كفاءة أداء المنظمات، وتقليل الوقت والتكلفة وزيادة Mekonnen, ) الجودة ورضا العملاء والموظفين 2017). ولقد بنى هذا المصطلح على القيادة التحويلة (Rottmann, 2017,151) ويعني لئي بالثقافة التظظيمية داخل المنظمة، والتي تؤثر على الموظفين وعلى التزامهم بالقواعد وحرصهم على المؤسسة (Novak, 2017, 67-74). ويركز هذا

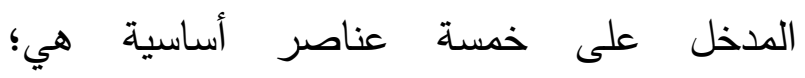

أرادت منظمات الأعمال بالقطاع الخاص إدخال

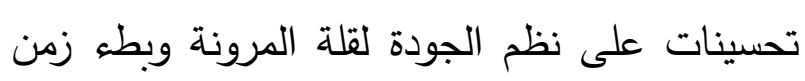
التنفيذ والبيرقراطية، وضعف القدرة على تلبية احتياجات العملاء، ولتحسين السرعة والدقة والمرونة والتكلفة؛ مما دفع إلى التغيير الجذري لطريقة العمل؛ لتحقيق أفضل أداء، ثم تبلور مصطلح الهندرة عام r99 ام عندما نشر مايكل هامر وجيمس شامبي

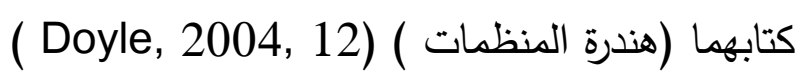
ويعتبر مفهوم إعادة هندسة العمليات الادارية (الهندرة) أحد مداخل التطوير الذي يركز على اعادة التصميم السريع والجذري للعمليات الادارية الاستراتيجية وذات القيمة المضافة، وكذلك للنظم، والسياسات، والهياكل التتظيمية، بهدف تحسين الأداء وزيادة الإنتاجية في المؤسسة .ويركز أسلوب الهندرة على التغيير الجذري في عمليات المؤسسة من أجل تطوير الإنتاجية في كمها وكيفها ومناولتها بهدف

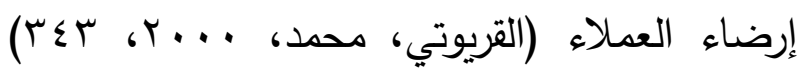
وقد عرف كل من مايكل هامر وجيمس شامبي في كتابهما الشهير (هندرة المنظمات) الهندرة بأنها " : إعادة التفكير بصورة اساسية واعادة التصميم الجذري للعمليات الرئيسية بالمنظمات لتحقيق نتائج تحسين هائلة في مقاييس الاداء العصرية وهي الخدمة، الجودة، التكلفة، وسرعة إنجاز العمل

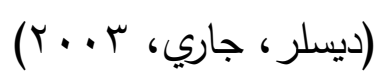

وتشمل الهندرة على عدد من المفاهيم ومنها : 
توثيق العمليات ضمن خرائط للتدفق تتضح معها صورة اجراءات العمل بطريقة سهلة وواضحة تمكن الجميع من العمل وفقًا لمنظومة محددة وواضحة. • التقليل من تداخل العمل وتكرار أداء المهام لـ حيث تعمل الهندرة على دمج العمليات المتثابهة في الدوائر المختلفة.

المبادئ التي تعتمد عليها عملية الهندرة : هنالك عدة مبادئ تعتمد عليها الهندرة تتمثل في :

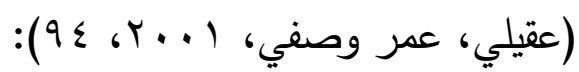
• تقوم الهندرة على إعادة تصميم العملية الواحدة من جديد بكامل مراحلها وخطواتها وذلك من بدايتها وحتي نهايتها، وكذلك تقوم على أساس تقنية المعلومات (نظام معلومات) الحديثة وتبني اللامركزية في عملية استخدامها، وتسعي الهندرة إلى دمج المهام الفرعية المتكاملة في مهمة واحدة، وتفويض الموظفين السلطة الكافية لأداء مهامهم بكفاءة بعد هندرة العمليات. • توفير المرونة الكافية في تنفيذ مراحل وخطوات العمليات، وتصميم العملية الواحدة بشكل يمكنها أن تئدي أكثر من عمل، وتقليل عدد مرات التدقيق والمراجعة لتوفير السرعة في الأداء، وتسعي الهندرة إلى زيادة القدرة التنافسية للمنظمات الكبيرة التي تستخدم تقنيات متقدمة. خصائص الهندرة وركائزها: يمكن توضيح أهم الخصائص التي تتميز بها الهندرة وركائزها التي تقوم عليها والتي يمكن القول بانه عند
السياسات، والتربية، والتعليم، واحتياجات المجتمع، والتقويم. (Rottmann, 2017,148) وفي مجال التعليم العالي والمؤسسات التعليمية هناك تعريف هام جدا وهو: اعادة هندسة العمليات الاداربة في التعليم العالي: هي عملية تطوير وتصميم جذرية تمس العمليات التعليمية كافة، وما يرتبط بها من مناهج وطرق بحثية على مستوي المستويات كافة من طلاب واعضاء هيئة تدريس واداريين (قوي،

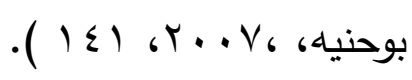
أهداف الهندرة: من أهم أهداف الهندرة ما يلي:(أنظر : عقيلي، عمر وصفي، |. . r، 90 \& بصنوي، محمد احمد، الغريب، هشام عبد الحميد، هبـ (، 1 . 1) : •التخلص من الروتين القديم وأسلوب العمل الجامد والتحول إلى الحرية والمرونة، وتخفيض تكلفة الاداء، وتحويل عمل الأفراد من رقابة واشراف متتالي يمارس عليهم إلى عمل يتمتعون فيه بصلاحيات وتحمل للمسؤوليات، والجودة العالية في الاداء، والسريعة والمتميزة. • إحداث التكامل والترابط بين مكونات العملية الواحدة، وتحقيق التخصصية في أداء الموظفين من خلال الانتقال من موظف المهام المتعددة إلى موظف المهام المتخصصة، مدا يضيف أداءً نوعيًا وتميزاً في الخدمة المقدمة. 
• الموظفون يتخذون القرارات (عبود، نجم، ا . .ب، .$(r \varepsilon$ • تكامل المركزية واللامركزية في الأعمال

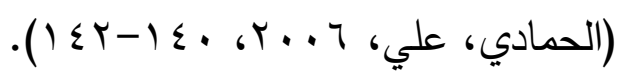
تطبيق الهندرة (إعادة هندسة العمليات الإداريـة) في

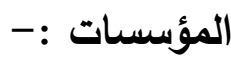

إن الإطار العام للهندرة يتضدن الآتي (الحناوي،

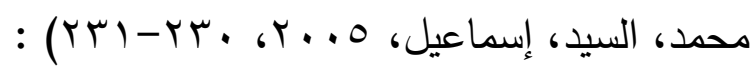
• دمج عدة عمليات في عملية واحدة، وتتم العمليات بالتتابع الطبيعي لها . • يمكن أن يكون للعملية الواحدة أشكال. • تخفيض نتط التوقف والمراجعة والتفتيش داخل

$$
\text { المؤسسة التي تستخدم إعادة البناء. }
$$

المنظمات التي تحتاج إلى تطبيق عملية الهندرة : يوجد ثلاث أنواع من المنظمات تحتاج إلى الهندرة: (هامر، مايكل، وشامبي، جيمس، 990 (1 ، · ): • المنظمات ذات الوضع المتدهور: وذلك للتغلب

$$
\text { على المشاكل التي تعاني منها. }
$$

• المنظمات التي في طريقها للتدهور: حتي

$$
\text { تستطيع استعادة مكانتها في السوق. }
$$

• المنظمات المتميزة والتي بلغت التفوق: بدافع

الطموح وتوسيع الفجوة بينها وبين المنافسين لها. متطلبات تطبيق عملية الهندرة: ا.توضيح خرائط العملية للمنظمة: الهندرة تعني بالعمليات لا بالمنظمات، وبالتحديد في مدخلات العملية مخرجتها، وبالنظر إليهما يمكن تحديد
توافرها او توفر بعضها قد تم تطبيق الهندرة في النقاط التالية : تكامل عدة وظائف في وظيفة واحدة. (رفاعي،

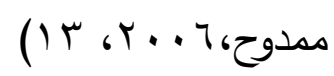
• تكنولوجيا المعلومات والدعم التقني للمؤسسات. ‘Chagas, 2017, ) \& (Lo, 2017,63) (221-235 • تخفيض أعمال الإصلاح إلى أدنى حد ممكن.

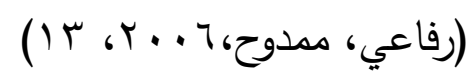

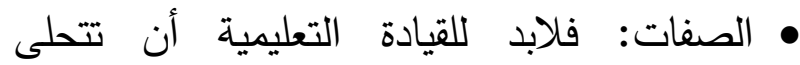
بالصدق والإخلاص والشجاعة والعزة والقدرة على Rottmann, ） التكيف والنفوذ والكفاءة. $(2017,149$ • المهارات : فلابد للقيادة التعليمية أن تتحلى بعدد من المهارات كالبصيرة وحل المشكلات وبناء فرق العمل، وحسن الإدارة، والاتصالات، والتوجيه،

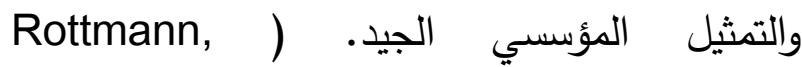
$(2017,149$ العمليات ذات أوجه وأبعاد متعددة: وفقاً لمتطلبات

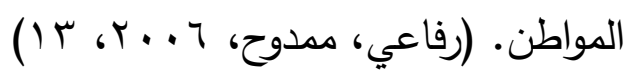
• دعم الإدارة العليا: وضرورة تغيير العوامل الإدارية والدواعي التظيمية (Mekonnen,2017). • يتم إجراء إعادة الهندسة للمواقع الأكثر حساسية

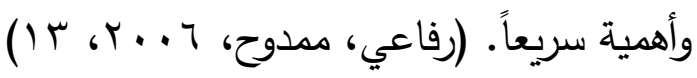
• تخفيض أعمال الاختبار والرقابة. (الحمادي،

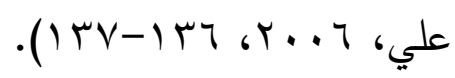


يختار المستشارين الخارجين ويراقب تطبيق العملية المهندرة على واقع العمل في المؤسسة. نتائج وفوائد تطبيق الهندرة : عند تطبيق الهندرة(اعادة هندسة العمليات الادارية) يترتب عليها العديد من النتائج والفوائد نذكر منها دمج وتوحيد الوظائف المختصة في وظيفة واحدة، وتغيير وحدات العمل من الاقسام إلى الغرق العملية، والتشجيع على التعليم إضافة إلى التدريب، ومساعدة العاملين على اتخاذ القرارات دون قصر هذه العملية

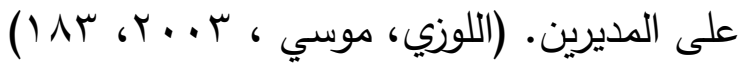
الأخطاء الشائعة والمتوقعة عند تطبيق الهندرة : إن عملية تطبيق الهندرة قد تعاني من بعض الأخطاء الشائعة في التطبيق، والتي قد تؤدي إلى الفشل في تحقيق أهداف وفوائد هذه العملية ومن بين الأخطاء ما يلي(هامر، مايكل، وشامبي، جيمس، $:(1990$ • محاولة إصلاح العمليات بدلاً من تغييرها تماماً، والتركيز على العمليات الإدارية واعادة تصميمها فقط، وتجاهل قيم الناس وثقافة المؤسسة، والقبول بالنتائج الطفيفة والتحسينات السخيفة، والتراجع من منتصف الطريق، ووضع العراقيل أمام الهندرة والتركيز على المظهر لا الجوهر، والسماح للسلوكيات الإدارية السائدة أن تمنع الهندرة من الانطلاق، ومحاولة إجراء عملية الهندرة من الأسفل إلى الأعلى.
مسميات العمليات (هامر، مايكل، وشامبي،

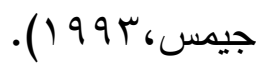
Y. اختيار العملية المناسبة للهندرة :- بعد رسم خرائط للعمليات توضيحية للعمليات داخل المنظمة، يمكن اختيار العمليات التي تحتاج لإصلاح، ومن الطبيعي أن يتم اختيار العمليات المعيبة والتي تظهر مشكلاتها للعيان (هامر، مايكل، وشامبي، جيمس، (199) (19). r.الاثخاص القائمون بعملية الهزدرة (هامر، مايكل، وشامبي، جيمس، و99 ()):- القائد الإداري يتركز دوره في الموافقة على عملية الهندرة ودعمها، ويجب أن يتمتع بنفوذ كاف لإقناع المنظمة والموظفين بأن العمل والجهد المطلوب لهندرة أي عملية يوجد ما يبرره .ويجب أن يملك هاجس إعادة اختراع المؤسسة لتصبح أقوى منافس في المجال. ع.صاحب العملية: هو المدير المسئول عن عملية ويشكل الفريق الذي يتولى هذه العملية، وهو أيضاً يحتاج للنفوذ وثقة الجميع حتى يستطيع توفير المصادر التي يحتاجها الفريق. ه. فريق الهندرة: من 5 إلى 10 أشخاص يتولون العمل الثاق، فهم يختبرون العملية الحالية ويتخيلون إعادة تصميمها وتطبيقها على الواقع الجديد .ويفضل أن يضم الفريق اعضاء من داخل المؤسسة وخارجها. 7. رئيس فريق عملية الهندرة: ويقوم بدعم صاحب العملية وفريق الهندرة، وتنسيق عملياتها .وهو الذي 


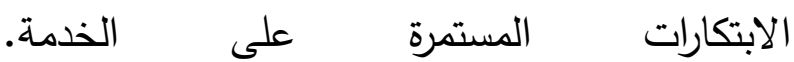

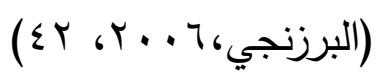

بعض الخبرات العالمية لتطبيق الجودة في مجال

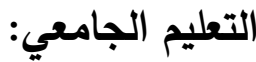
اولا تجربة الولايات المتحدة الامريكية : (مصطفي،

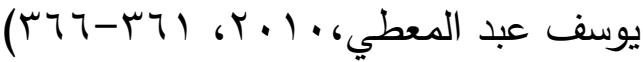
خلال فترة التسعينيات من القرن الماضي لجأت بعض المؤسسات الامريكية إلى اعادة هندسة العمليات الادارية بها وذلك بهدف تحقيق التطوير الجذري والتخلص من الاجراءات التظيمية القديمة.وبدراسة النموذج الذي تم اتباعه في الولايات المتحدة الامريكية لهندرة التعليم الجامعي يلاحظ انه تم تقسيم العمليات داخل الجامعات إلى قسمين؛

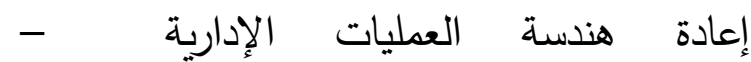
Reengineering in Administrative operations وإعادة هندسة العمليات الاكاديمية - Reengineering in Academic operations اولاً :إعادة هندسة العمليات الإداريـة : وتتم من خلال ما يلي: (مصطفي، يوسف عبد

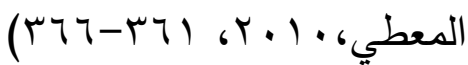
التقويض: وهو امتلاك السلطة وتحمل المسئولية

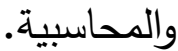
• الموظف متعدد الوظائف: ففي المنظمة المعاد هندستها يجب ان يكون عضو الفريق ذا موهبة
• تعيين شخص لا يفهم ما هي الهندرة لقيادة المعركة، ودفن الهندرة في كومة من جداول الأعمال والأوليات، وعدم تخصيص أية موارد لإجراء العملية، وإجراء عملية الهندرة والمدير العام على وشك : عامك التقاعد، والتركيز على التصميم واهمال الهدف، ومجاملة الإدارات المختلفة حتي لا يغضب أحد، والرضوخ للضغوط ومقاومة التغيير • صعوبات تطبيق الهندرة: تواجه الهندرة العديد من الصعوبات منها: (Omidi,2016, 425-432) العوامل الفنية: وتشمل؛ إدارة التغيير لتشجيع العاملين على التعلم واستمرارية النمو لتغيير مؤسساتهج، وكذلك عملية الإدارة وإشراك جميع العاملين في عمل رؤية جديدة للمنظمة. ثقافة المنظمة: وهي المعتقدات السائدة في المنظمة وثقافة المنظمة التي تحدد هوية الأفراد ومدى مشاركتهج، والتكامل والتوافق فيما بينهم. • العوامل البشرية: مثل خوف العاملين من فقدان الوظيفة، وعدم التيقن من نتائج التغيير، وعدم الارتياح والقلق من أماكن العمل. دور الهندرة في تحقيق الجودة في التعليم الجامعي في ظل تحديات العصر الرقمي: من خلال ما تم من دراسات سابقة وجد ان هناك البعض ممن يحدد دور الهندرة في تحقيق الجودة، اذ يمثل تغيير اسلوب المنظمة في التفكير والتعليم والعمل وان التحسين المستمر للخدمة يعني ادخال 
في هذا النموذج يجب ان يكون للطلاب مدخلات في تصميم عملية التدريس والتعلم حيث المهام ترتكز على عمل الفريق team work وفي انشطة البحث يجب ان يتاح للطالب حرية اختيار المواد والادوات لإنجاز المهام وتكون المعرفة بتطبيقات الانترنت امرا

ضروريا للدخول على المواد التعليمية ونقلها. • مناهج التعليم عن بعد: حيث صبح التعلم عن بعد في الوقت الحالي جزء اساسي من أي استراتيجية لتطوير التعلم وتوفيره للمجتمع فهو احد البدائل الرئيسية وتتصف انشطة عملية التعليم والتعلم في التعلم عن بعد بانها شيقة تجاوبية تفويضية وموجهة نحو الناتج وهي انشطة غير محدودة لزمن او مكان او اجراء او موارد وهو يعتمد على الكومبيوتر وهو ضروري لتحقيق مجتمع تعلم جيد . القسم الثاني: التدربس والتعليم: وتنقسم عملية التدريس والتعليم إلى: (مصطفي،

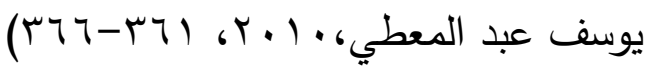
• التكنولوجيا في قاعة التدري: ان التكنولوجيا بفردها لا يمكنها الوفاء بأهداف الجامعة والحصول على النتائج المرجوة من عمليات التّريس والتعليم حيث يجب ان تمتلك الجامعة بنية تحتية كافية بهدف تصميم وتوجيه المنهج الموجه تكنولوجيا. • كفاءة اعضاء هيئة التدري: حيث ان نمو اعضاء هيئة التدريس مهنيا وعلميا هو المفتاح الاساسي لفتح عالم جديد من التعلم امام الطلاب كاب فاذا كان اعضاء هيئة التدريس بالجامعة يتسمون
متعددة الابعاد كما يجب ان يتمتع بالمعرفة الاساسية حول ادوار الاعضاء الاخرين في الفريق. • تحول المشرف إلى مدرب: القائد الجيد في المنظمة المعاد هندستها هو الشخص المسئول عن نمو اعضاء المنظمة فبدلا من الترهيب نجد المودة بين القادة بعضهم البعض والصراحة في اتخاذ القرار وتفهم تصميم العملية والمعرفة بالعمل الجماعي. إعادة هندسة العمليات الأكاديمية: ونلاحظ من الشكل السابق ان اعادة الهندسة الاكاديمية تنقسم إلى قسمين: القسم الأول: تصميم المناهج: حيث يتم تحويل الانشطة الموجهة نحو العملية إلى انشطة موجهة نحو الناتج مع التركيز بوجه خاص على تقوض الطلاب في انشطة التعلم ويجب ان تكون التكنولوجيا جزء من المناهج وهنا نلاحظ ان المناهج تتقسم إلى: (مصطفي، يوسف عبد

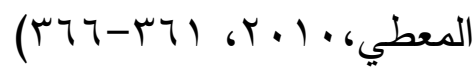
الطلاب قبل التخرج (مناهج المرحلة الاولي): يكون هدفها الاساسي مواجهة احتياجات سوق العمل بحيث تعد المهام المعتمدة على الكومبيوتر مثل المشاركة في مناقشة جماعية والاتصال والبريد الالكتروني واستخدام المصادر التعليمية من خلال الانترنت اضافة لمنهج الطالب الخريجون (مناهج الدراسات العليا) :حيث ان انشطة الدراسات العليا توجه من انشطة ترتكز على المعلم إلى انشطة ترتكز على المعلم والطالب حيث 
المكتبة ومدير ت تكنولوجيا المعلومات وهو يمثل الخدمات التقنية، وفي جامعة ميلاند تقوم الادارة العليا بتعيين اعضاء هيئة التدريس من اجل التغيير باعتباره الزاميا لتحديد الوسائل لإدارة تكون اكثر فاعلية ولها كفاءة عمليات الدعم الاداري اما في الجامعة الثمالية الغربية NWU) يقوم اعضاء هيئة التدريس بإعادة تصميم لعمليات التعليم والتعلم، ويلاحظ ان الغرض من انشاء فريق الهندرة متعدد التخصصات تحقيق هدفين وهما:( Allen, D.K. )

\& Fifield, N., 1999 • أعضاء الفريق يكون لهم رؤية شاملة لتخصصهم. • أعضاء القريق بكون لهم القدرة على التشاور في نطاق واسع من مجموعات مختلفة من الافراد المشاركين في هذه العملية للحصول على الوصف

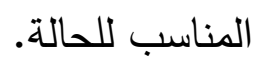
ثالثا : تجربة ماليزيا والفكرة الاساسية لعملية اعادة هندسة العمليات الادارية بجامعات ماليزيا تعتمد على التطوير في التعليم الجامعي من خلال البعد عن النظام الهرمي ونقا السلطة إلى الادارات الفنية وبذلك يكون اعادة الهيكلة تبعا لاحتياجات التغيير بالمنظمة مع التركيز على تطبيق استخدامات تكنولوجيا المعلومات والاتصالات في عملية التعليم والتعلم ، وبناء على ذلك يمكن توضيح عملية الهندرة في التعليم الجامعي في ماليزيا كما يلي: :SALLEH,KAHIROL) MOHD\& SULAIMAN, NOR LISA, 2012)
بالكفاءة والمهارة للتدريس للطلاب فسوف تتمكن الجامعة من احراز نجاح ملحوظ في مجال استخدام. كفاءة الطالب: يلعب اعضاء هيئة التدريس دورا اساسيا في اشتراك الطلاب في مجال تكنولوجيا الكومبيوتر ففي ظل عملية التعليم والتعلم اليوم نجد ان غالبية الطلاب يستخدمون تطبيقات الانترنت للحصول على المصادر التعليمية واستخدام البريد الاككتروني بوصفه جزءا شائعا من وسائل الاتصال بين الطلاب والاساتذة والطلاب. ثانيا تجربة المملكة المتحدة تم تطبيق عمليات اعادة هندسة العمليات الادارية (الهندرة ) في عدد من المؤسسات الجامعية في المملكة المتحدة باعتبارها استراتيجية ادارة التغيير وتركز هذه المؤسسات على اعادة هندسة الخدمات الادارية وهناك ايضا محاولات لإعادة تصميم التعليم والتعلم بالجامعات. ومن الجامعات التي قامت بتطبيق اسلوب اعادة هندسة العمليات الادارية بالمملكة المتحدة جامعة ميلاند والجامعة الشمالية الشرقية (NEU) والجامعة الشمالية الغربية (NWU) وجامعة يوركثاير وهي تعد واحدة من اكبر الجامعات الاهلية في المملكة المتحدة. وتعتمد عملية الهندرة فيهذه لجامعات على تفويض الادارة العليا (المسئولية في حالة التنفيذ) إلى الطبقة الاقل من الادارة وفريق الهندرة يكون مكون من مدير اداري كبي من ادارة الجامعة ومدير المحاسبة المالية من الادارة المركزية ومدير خدمات المعلومات وهو يمثل 
فقط، بل إنها تطرق أبواب عملية التعلم أيضا، فنجد Active ) (ALE) إعادة هندسة التعلم النشط (Learning in Engineering Education وذلك من خلال شبكة دولية غير رسمية لإعادة هندسة التعليم من خلال التعلم النشط، ويتشكل مجتمع الرابطة من المعلمين وواضعي المناهج الدراسية، والباحثين في التعليم، ومديري البرامج الدراسية والمهتمين بأساليب التعلم النشط. وبدأت هذه الرابطة على جانبي المحيط الأطلسي عام .... . . والنشاط الرئيسي لهذه الشبكة هو تتظيم ورش عمل سنوية في أجزاء مختلفة من العالم (ALE,2017) • ويهدف هذا المدخل إلى تحسين ممارسات المعلمين حتى يكون التعليم فعالا، والوصول لأفضل تعلم للطلاب من خلال النشاط، وتوفير أفضل الممارسات. (Christie, 2017, 5-16)

\section{أهم تحديات العصر الرقمي:}

لقد غيرت الثورة الرقمية أدوار المؤسسات التربوية في إعداد المواطنين لعالم المستقبل الذي قد يبدو مختلفًا تمامًا عن عالم اليوم، مما يفرض العديد من

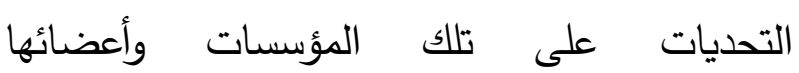
(Meilleur, 2018)، وعلى رأسها المعلمون في كل مكان في العالم الذين يواجهون تحديات جديدة كل يوم فيما يتعلق بالطلاب واحتياجاتهم الفردية والأجهزة والبرامج الجديدة والاحتياجات التتموية الخاصة بهم

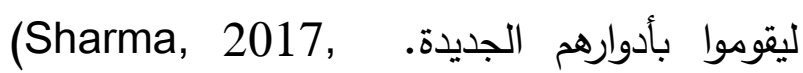

ا ـ اعادة هندسة العمليات الادارية : وذلك من خلال التغيير من التسلسل الهرمي إلى نظام التسلسل المسطح عن طريق تدريب الادارة على تحمل مزيد من المسؤولية لتحسين الثقافة الداخلية بالجامعة. r. اعادة هندسة عمليات التعليم والتعلم :وذلك من خلال التركيز على ثقافة التغيير والاستخدام الاوسع لتقنية المعلومات. وقد لوحظ ان تطبيق الهندرة بالتعليم الجامعي بماليزيا يواجه بعض العقبات منها محاولة اصلاح العمليات بدلا من التغيير الجذري لها واعادة تكوينها، وعدم التركيز على العمليات وعدم اختيار العمليات التي سيتم هندرتها بالشروط والاسس التي اختيرت لذلك. تجاهل معتقدات ومفاهيم العاملين حيث تتطلب عملية الهندرة اعادة تشكيل المفاهيم وتكوين اتجاهات العاملين، والاكتفاء بالنتائج والنجاح المتواضع، والتراجع المبكر عن عملية الهندرة . عدم وجود الدعم الكافي من الادارة التنفيذية وذلك يعتبر من اكثر الاسباب التي تؤدي إلى فثل مشروعات الهندرة في كثير من التجارب هندرة العمليات الادارية في المؤسسات الجامعية: بما ان العمليات الادارية هي اعمال ونشاطات محددة يؤدي تنفيذها إلى حسن سير العمل في المؤسسة وبالتالي تحقيق اهداف المؤسسة المتمثلة في البقاء والنمو والازدهار (عليمات، صالح ناصر ،

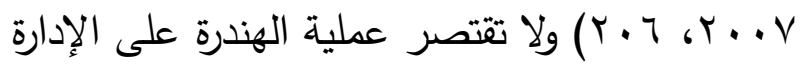


(Meilleur, 2018)، كما ينبغي إحداث تغيير في العملية التعليمية، وبناء السياسات والاستراتيجيات والتطبيقات الفاعلة لدواكبة تلك التغيرات الحديثة.

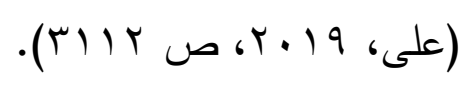

• تعدد أدوار هيئة التدريس في ظل التل العصر

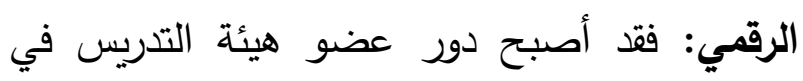
العصر الرقمي أكثر صعوبة حيث تضمن القيام بالعديد من المهام في نس الوقت، من تخطيط وتتفيذ وتتويم والتي لم يعد يناسب القيام بها بالطرائق التقليدية، أصبح مطالب بأدوار أخرى كثيرة في نفس لنس الوقت منها الإسهاب والتتظيم والتجميع والغربلة والنمذجة لتلك المعلومات المتدفقة عبر الإنترنت، بالإضافة إلى توجيه وإشاد الطلاب، (سيلفا،

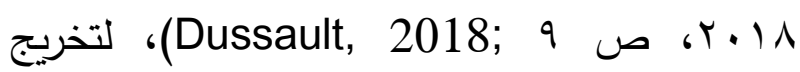
خريجين على مستوى عال من التأهيل بمهارات القرن الحادي والعشرين، وكذلك التكنولوجيا الدتغيرة على الدوام (Sharma, 2017, p.12). • عدم مواكبة المناهج وطرائق التدريس الحالية

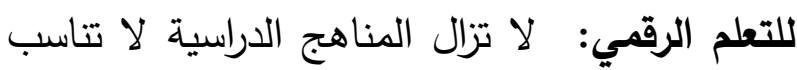

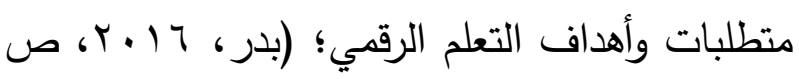
9 (1)، نظرا لاستغراقه وقتا أكبر، وخاصة في العئ العصر الرقمي الذى يفرض أن يتم التعلم وفق قدرات كل طالب (Dussault, 2018)، ومن ثم يتعين تحديث البرامج والمناهج التعليمية، وابتكار وصياغة طرائق نقائق

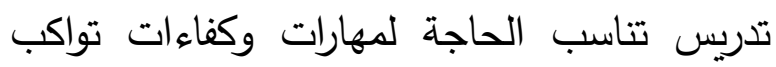

ومن أبرز التحديات التي تواجه العصر الرقمي ما يلي: • ضعف قدرة الطبقات المهمشة على الاستفادة من العصر الرقمي: فمن يتمكنون من الوصول للإنترنت يستطيعون متابعة سير التعلم الرقمي التئي بأساليبه ووسائله المختلفة، في حين سيحرم آخرون ممن لا يملكون الكهباء أو أجهزة الهواتف الذكية،

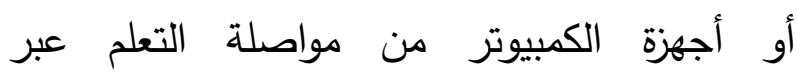
الإنترنت، وهو ما يمثل تحديًا للمعلمات الراغبات في التئي استخدام التقنيات الرقمية في التدريس وممارسات التعلم ; David, et al., 2020, p. 4) Catalano, 2019, p. 27 • ضعف البنية الأساسية لتكنولوجيا المعلومات: يغلب على تقنيات الاتصال السريع بالدول النامية عدم كفايتها ونقص فعاليتها مقارنة بتقنيات الاتصال بالدول المتقدمة، هذا بالإضافة إلى مشاكل التقنية

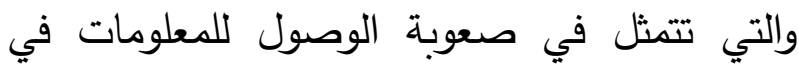
نس الوقت، مما يؤثر سلبا على استخدام طرائق

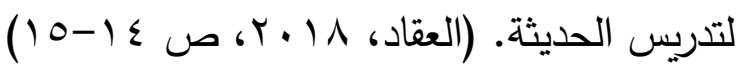
• إعداد جيل متعلم لمستقبل لم تتحدد معالمه التكنولوجية بعد: فيجب إعداد جيل لعالم جديد عالمي التقنية وسريع التغيير لم تتحدد ملامحه بعد إليد

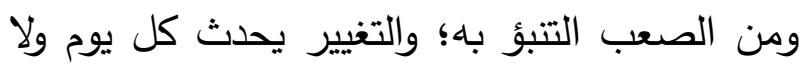
يزال؛ فالثورة الرقمية تحمل معها تغييرات اجتماعية واقتصادية، وهو ما يتطلب إعطاء الطلاب الأساس القوى الذى يجعهم قادرين على بناء معارفهم 
يحتاجونها للتدريس في العصر الرقمي، فبرامج الإعداد لا تهتم بإحداث تغيير واسع في الاستخدام

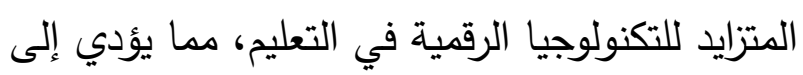
اتساع الفجوة بين النظرية والتطبيق في التدريس الحقيقي في قاعات الدراسة، وهو ما ينعكس في لهي قصور أداء عضو هيئة التدريس في تعزيز كفاءات

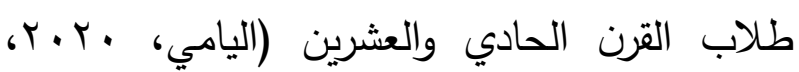

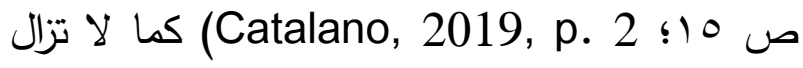
برامج التدريب تعاني من القصور نتيجة اتباعها الطرائق التقليدية في تدريب عضو هيئة التدريس على مهام التدريس التقليدية، كما أن التدربب على هي المهام الجديدة ما زال محدودًا وليس بالكفاءة المطلوبة، مما ينعكس في عدم كفاية أساليب التدريس وبيئات التعليم والتعلم لدعم حاجات التعلم في العصر الرقمي (بدر، 7 ( ـ ب، ص ع ع (). • إقناع أولياء الأمور بمتطلبات التعليم والتعلم الرقمي: فمن أكبر التحديات التي تواجه عضو هيئة التدريس هي إيجاد سبل لإقناع أولياء الأمور أن

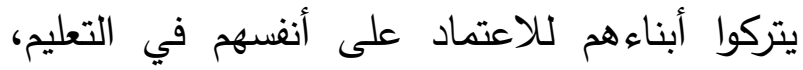
حيث إن الاهتمام الزائد منهم يحمل دعوة للأبناء

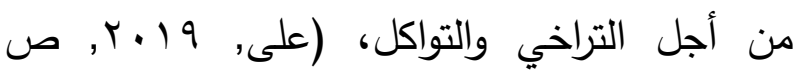
r/1 مب)، كما أن مواقف الوالدين المتعلقة بقضاء

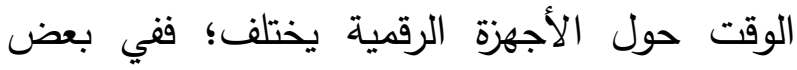

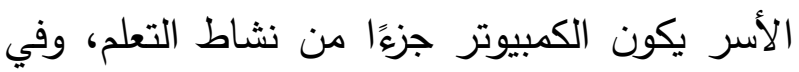

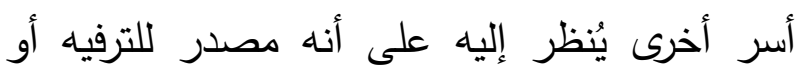
ضياع للوقت (Catalano, 2019, p. 26).
(Catalano, التغير في التكنولوجيا وسوق العمل 2019, p. 27) ارتفاع الكثافات في قاعات الدراسة: تعد ارتفاع الكثافة الطلابية في العديد من المؤسسات في بلاد عديدة من أهم التحديات التي تؤثر على فعالية أداء عضو هيئة التدريس في العصر الرقمي؛ حيث إنه

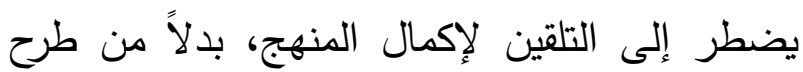
الأسئلة واستكثاف (Sharma, 2017, p.12). • تفوق بعض الطلاب تكنولوجيا أحيانا على أقرانهم وعلى أعضاء هيئة التدريس : لقد ألقت

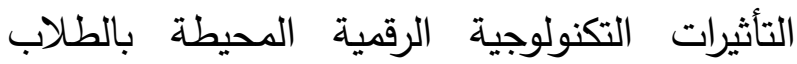
بظلالها عليهم، فلم يتغير شيء أكثر من الطلاب

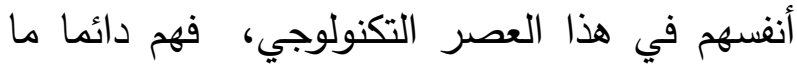
يتواجدون حول جهاز إلكتروني متصلاً بالإنترنت، ومن خلاله يمكنهم الوصول إلى معارف متعددة، فأصبحوا أكثر دراية، Sharma, 2017, p.12; Giraffa. \& Marczak, 2012, pp. 2267.2269). التدريس وبين والطلاب من جانب، وبين الطلاب بعضهم البعض من جانب آخر؛ فتعامل أعضاء هيئة التدريس مع التكنولوجيا يتسم بتحكم بطيء بمصادر معلومات محدودة، ومعالجة فردية لمهام

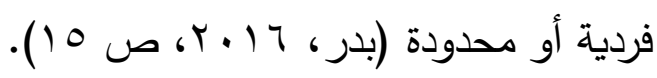
• قصور برامج إعداد عضو هيئة التدربس وبرامج التدريب: تعاني برامج إعداد عضو هيئة التدريس من هن هئ

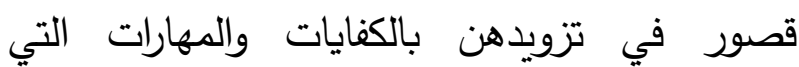


الادارية وتزايد اعداد الطلاب ومحدودية مصادر التمويل الحكومية من الدولة. (3) دراسة ( المالكي، r... (Y) ) بعنوان : "الأبعاد الإدارية والأمنية لهندرة العمليات الإداربة وعلاقتها لعانها بالأداء الوظيفي دراسة ميدانية على وكالة الآثار والمتاحف بالمملكة العربية السعودية". والههف من هذه الدراسة التعرف على الأبعاد الإدارية والأمنية لهندرة العمليات الإدارية وعلاقتها بالأداء الوظيفي الإداده والاينيه في وكالة الآثار والمتاحف واستخدمت المنهرج الوصفي، وأبرز نتائج هذه الدراسة وجود مركَّزية في ولي اتخاذ القرار وعدم تفويض السلطة، وبيروقراطية الإجراءات، والحاجة إلى إعادة تأهيل الموظفين

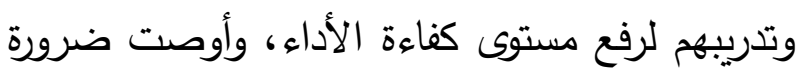
تمتع الموظفين ببعض الثقة التتظيمية الداعمة لجهود

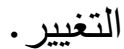
(4) دراسة (الثهراني ، V. V. Y) بعنوان: " اعادة هندسة اساليب التعليم الجامعي لمواجهة متطلبات عصر ثقافة المعلومات - نموذج مقترح لجامعة أم

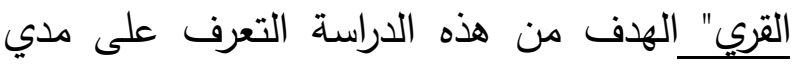
المام أعضاء هيئة التدريس بجامعة ام القري بالحاسب الالي ومدي استخدامهر له في عملية التدريس واستخدت الدراسة المنهج الوصفي، وأبرز نتائج هذه الدراسة هو إلمام اعضاء هيئة التدريس بجامعة ام القري عالي المستوي في مهارات الاستخدام الشخصي وبينما هو متوسط في مهارات

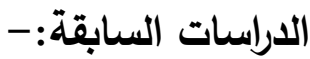
(1) دراسة (الحارثي ، r . . ب) بعنوان: " خفض التكاليف في مؤسسات التعليم العالي باتباع اسلوب لهوبي هندسة العمليات الاداربة كليات جامعة البنات في المملكة العربة السعودية نموذجاً، الهدف من هذه الدراسة اقتراح نموذج لخفض التكاليف وتحسن الاداء في كلية التربية للبنات بالمملكة العربية السعودية باستخدام اسلوب الهندرة، واستخدمت المنهج الوصفي، وابرز نتائج الدراسة تتم العمليات مركزيا بينما تعد الكليات جهات تتفيذية فقط ومعظم الاعمال تتم يدوياً وتشكيل اللجان بما يشتت جهود اعضاء العملية التعليمية وههم في حاجة إلى المراقبة وانتهت لوضع نموذج لرفع الجودة وتقليل الهرد ..

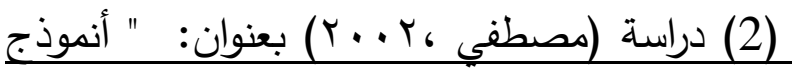
مقترح للتطبيق مفهوم اعادة هندسة العمليات في التعليم الجامعي" الهدف من هذه الدراسة الوقوف على واقع التعليم الجامعي المصري ومفهوم اعادة هندسة العمليات ومتطلبات تطبيقها في التعليم الجامعي ومحاولة وضع أنموذج مقترح لإعادة هندسة عمليات التعليم الجامعي المصري في ضوء الخبرة الامريكية. واستخدمت المنهج الوصفي، وابرز نتائج هذه الدراسة غياب الرؤية الشاملة وعدم توافر

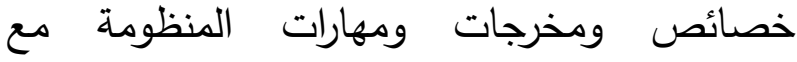
متطلبات سوق العمل وضعف الموارد التعليمية (المكتبات - مصادر المعلومات) وتضخم الهياكل 
وإلى مواقع التعليم عن بعد في التعليم العالي، واستخدمت الدراسةالمنهج الوصفي، وابرز نتائج هذه الدراسة اقتراح نموذج لمزيد من التحسينات التي من

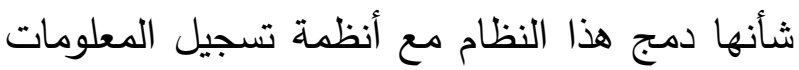
وما يقلل بالتالي من حاجة الجامعة إلى ادخال المعلومات حول الطلاب وتوفير قاعدة مرنة لعمليات اعادة التفكير وتنظيم جدولة الاختبارات وقد ساهم ذلك في كثف الاخطاء وزيادة الفاعلية بالاضافة إلى الى خفض التكالف الكلية.

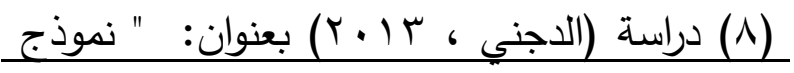

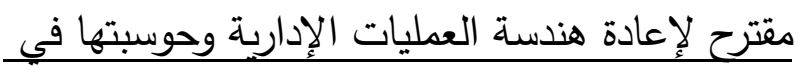
مؤسسات التعليم العالي (الجامعة الإسلامية دراسة

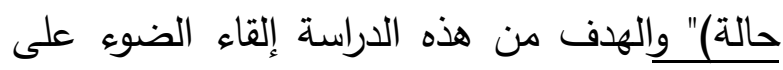
الجوانب المختلفة لأسلوب إعادة هندسة العمليات

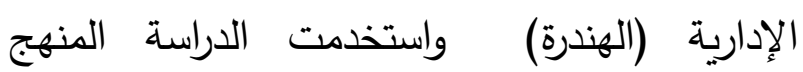
الوصفي، وأبرز نتائج هذه الدراسة أنه يوجد بالفعل الدانل

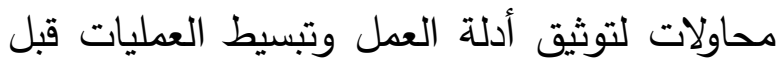

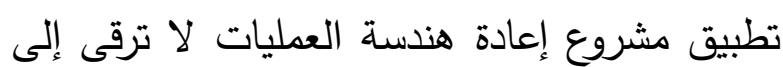

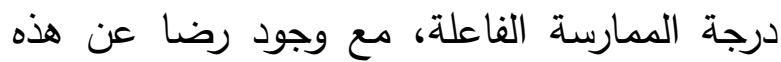
التجربة لما حققته من نتائج على صعيد إعادة ترتيب العمل وتتظيمه وفق خطوات محددة وموثقة.

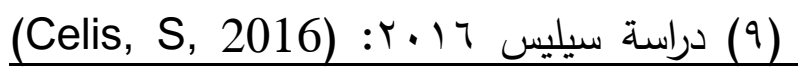
بعنوان "إعادة تصميم وهندرة التعليم في تشيلي: كيف تتتش المؤسسات ا في عملية إصلاح وطني طموح" وِالهدف من هذه الدراسة عمل تحليل استقرائي لهندرة التعليم بما يشمله من مناهج دراسية ونظام بيئي
الاستخدام في التدريس ويعتبر قليل في مهارات اعداد البرامج والدروس.

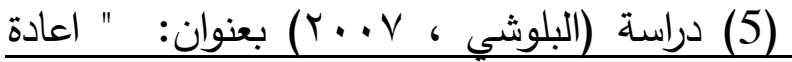
هندسة العمليات الادارية وامكانية تطبيق منطلباتها في كليات التربية بسلطنة عمان " الهدف من هذه الدراسة التعرف على الاسس الفكرية لإعادة هندسة العمليات الإدارية ومتطلبات تطبيقها في كلية التربية بالرستاق وكلية التربية بامعة السلطان قابوس بسلطنة عمان ، واستخدمت الدراسة المنهج الوصفي، لهن

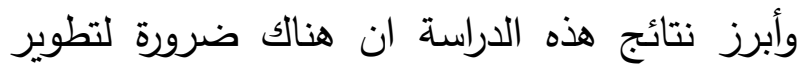
لعمليات الادارية لكليات التربية في ضوه لنوره هندسة

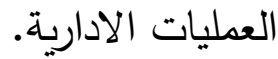

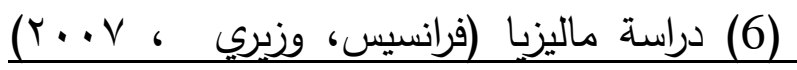
بعنوان: " " عوامل نجاح عملية اعادة هندسة العمليات الادارية في التعليم العالي" الهدف من هذه الدراسة فحص عوامل نجاح عملية اعادة هندسة العمليات الادارية في التعليم العالي، واستخدمت المنهج الوصفي، وِأبرز نتائج هذه الدراسة ان هناكي عدد من العوامل لنجاح عملية اعادة هندسة العمليات الادارية في التعليم العالي.

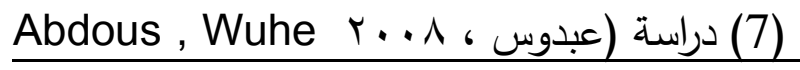

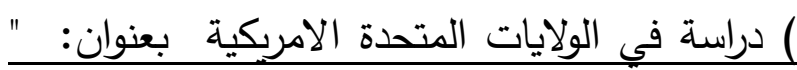

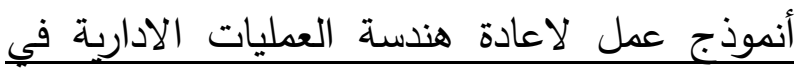
التعليم العالي" والهدف من هذه الدراسة استبدال الاختبارات المكتوبة باخري الكترونية من اجل تقليل التكاليف المتعلقة بارسال واستقبال الاختبارات من بن اجن 
الوصفي، وِأبرز نتائج هذه الدراسة ضعف استخدام

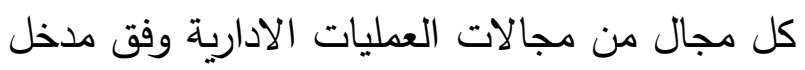
اعادة هندسة العمليات الادارية . (Jha \& O'Brien, 2019) دراسة (I T) بعنوان"إعادة هندرة التعليم العالي لتحليل البيانات الكبيرة" هدفت الدراسة إلى دمج تحليلات البيانات

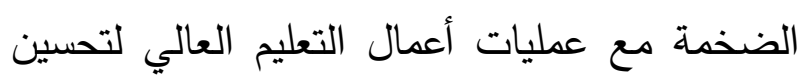
إبقاء الطلاب على المسار الصحيح حتى التخرج و خفض معدلات التسرب وإبقاء الطلاب على المسار

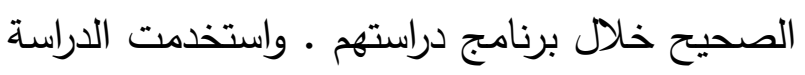
المنهج الوصفي التحليلي. وتوصلت الدراسة إلى : تقديم نموذجًا جديدًا لعملية هندسة التعليم العالي.

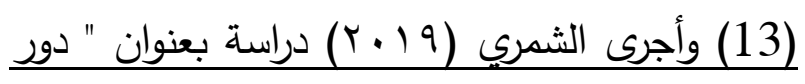
التعلم الرقمي في التتمية المهنية للمعلمين" وهدفت إلى تعرف دور التعلم الرقمي في التتمية المهنية للمعلمين، وانعكاس ذلك على تدريسه أثناء الخدمة

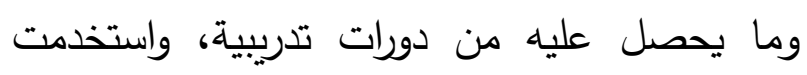
الدراسة المنهج الوصفي، وتوصلت الدراسة إلى أن تدريب المعلمين قبل وأثناء الخدمة على كيفية التعامل مع التعلم الرقمي أصبح ضرورة لابد منها،

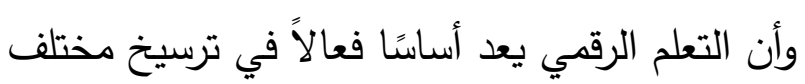
المعلومات والبيانات في بيئات التعلم.

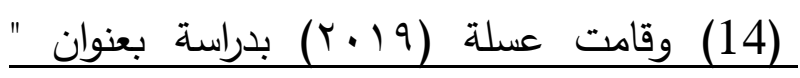

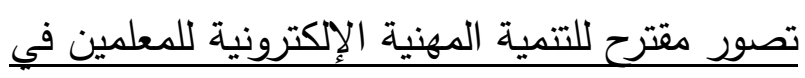
ضوء تحديات العصر الرقمي" وهدفت إلى التوصل لتصور مقترح للتمية المهنية الإكترونية للمعلمين.
للإدارة وتحسين البنية التحتية، والمبادئ التوجيهية

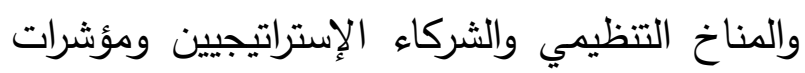

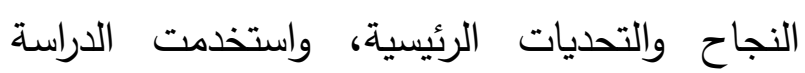
المنهج الوصفي، وأبرز نتائج هذه الدراسة أن الهندرة تتطلب خمسة مجالات أساسية للعمل بنجاح تتمثل في؛ مواءمة المناهج، الإدارة وتحسين البنية التحتية، لتهاتل

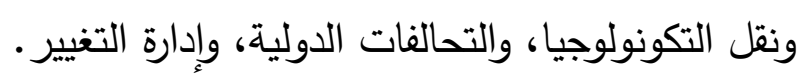

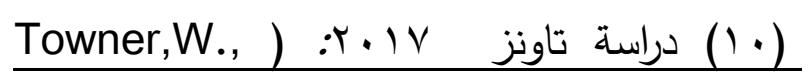

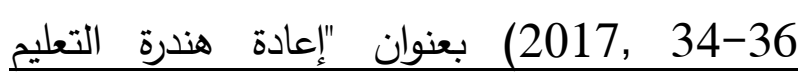

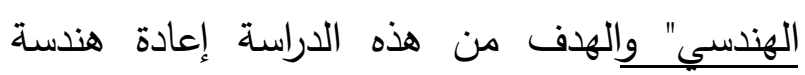

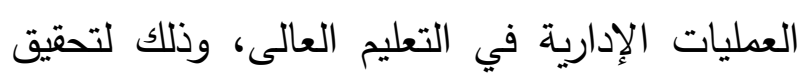

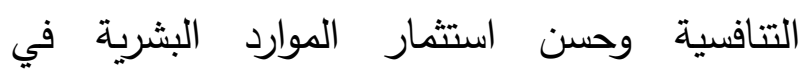
المؤسسات التعليمية، وتحقق الأهداف بشكل أفضل، التصوليه

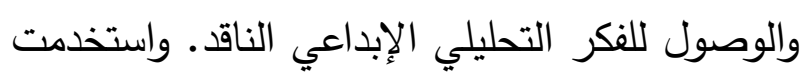
الدراسة المنهج الوصفي، وتتاولت الدراسة تحليل

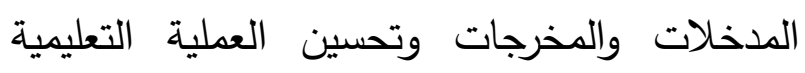

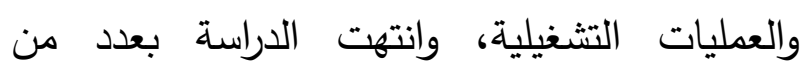
التوصيات في هذا السياق.

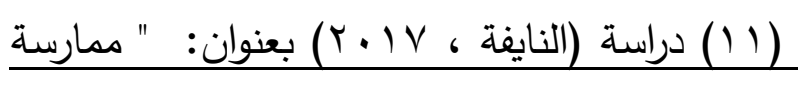
العمليات الادراية في جامعة تشرين وفق مدخل

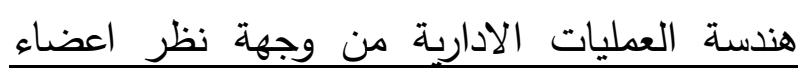

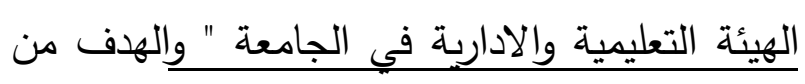
هذه الدراسة التعرف على درجة ممارسة العمليات الادراية في كليات جامعة تشرين وفق مدخل هندسة لتهرة العمليات الادراية من وجهة نظر العاملين فيها من أعضاء الهيئة التعليمية واستخدمت الدراسة المنهج 
أهمها عدم امتلاك المعلمين نفس الأدوات والمعرفة الرقمية، وأوضحت أنه من فرص العصر الرصن الرقمي

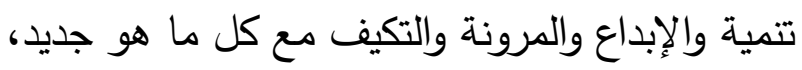
وتحول دور المعلم من الملقن للمشجع والموجه والمراقب للطلاب، وتوفير البنية التكنولوجية والأدوات

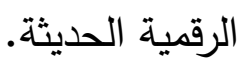

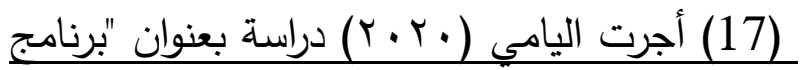
تدريبي مقترح لتنمية مهارات التدربس الرقمي لدى معلمات التعليم العام بالمملكة العربية السعودية" وِدفت إلى استتناج مهارات التدريس الرقمي بالقرن الحادي والعشرين، وتعرف واقع امتلاك المعلمات

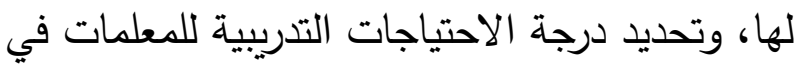
تلك المهارات من وجهة نظرهن، وقد استخدمت الدراسة المنهج الوصفي التحليلي، وتوصلت الدراسة إلى ضعف تأهيل المعلمات في مجال التدريس وتئي الرقمي أثناء برامج أعدادهن، وعدم كفاية البرامج التدريبية المقدمة لهن أثناء خدمتهن، وأوصت ودماه الدراسة بالاهتمام بتحديد الاحتياجات التدربيية

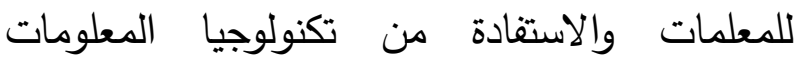
والاتصالات في توسيع نطاق التدريب. أهم الاورس المستفادة من لدراسات السابقة:

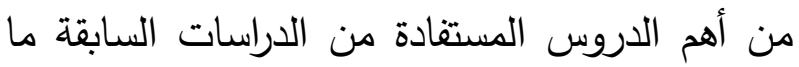
يلي: الهندرة هي التطور الطبيعي للعصر الرقمي وما يفرضه من تحديات عالمية.
واستخدمت الدراسة المنهج الوصفي، وتوصلت الدراسة إلى مجموعة من النتائج أبرزها: ندرة البرامج المرتبطة بتنمية مهارات المعلم في استخدام تكنولوجيا التعليم والاتصال والمعلومات الحديثة وتوظيفها في إثراء بيئة التعلم داخل الفصل وخارجه، وانتهت الدراسة بتقديم تصور مقترح يمكن من خلاله الارتقاء

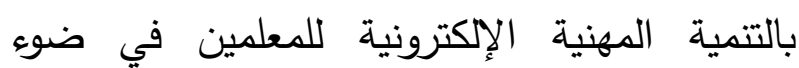
تحديات العصر الرقمي. (19) Rossikhina وقامت روسيخينا بدراسة بعنوان " مشكلات رقمنة التعليم في أوكرانيا" وِهدفت إلى تحليل مميزات وعيوب رقمنة التعليم في

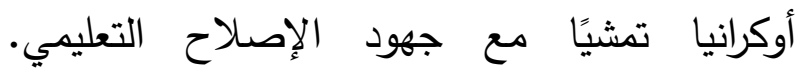
واستخدت المنهج الوصفي، وتوصلت الدراسة إلى أن من أهم مميزات رقمنة التعليم هو التوافر المجاني لوسائل ومصادر المعرفة وتتوعها ولكن من عيوب الميا ومشاكل رقمنة التعليم ضعف استعداد المعلمين للتحول الرقمي وأوصت الدراسة بضرورة تعديل السياسات التعليمية الخاصة باختيار وإعداد معلمي لريكي العصر الرقمي الجديد بما يتوافق مع قدرات الطلاب باتيات التكنولوجية الجديدة والمتميزة. (16) وقام كاتالانو Catalano وآخرون (19) بدراسة بعنوان " فرص وتحديات التعليم في العصر الرقمي" وهدفت إلى تعرف فرص وتحديات التعليم في العصر الرقمي في رومانيا. واستخدمت الدراسة المنهج الوصفي التحليلي. وتوصلت الدراسة لمجموعة من التحديات التي تواجه رقمنه التعليم من 
• أهيـة المكون التكنولوجي في هندرة المؤسسـات الدراسة الميدانية:

تمثلت الدراسة الميدانية فيما يلي: الدراسئ:

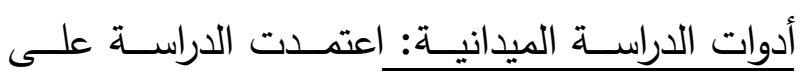
استبانة موجهة إلى أعضاء هيئة التدريس من الذكور

والإناث بالكليات النظرية والعملية بجامعة حائل.

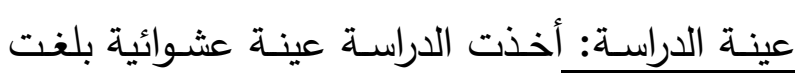

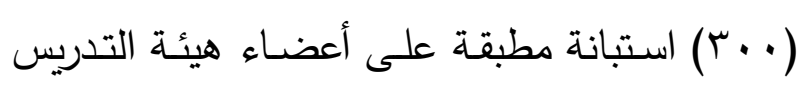

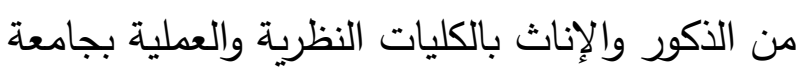

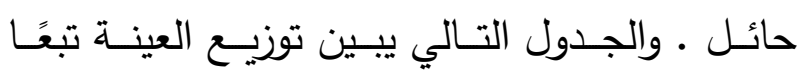
بشكل عام والتزبوية منها بشكل عام.

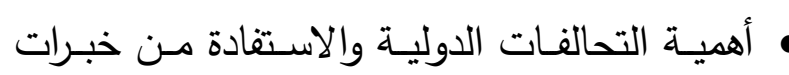
الآخرين في عملية الهندرة. • أهمية تحسين البنية التحتية في عملية الهندرة.

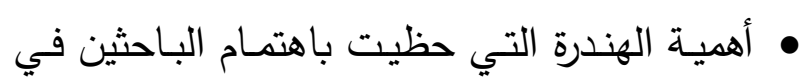

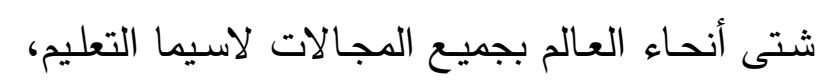

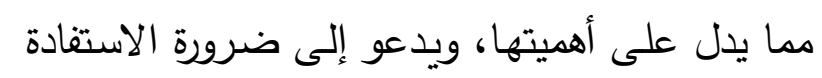
منها في تطوير الواقع. الهندرة تتطلب إدارة التغيير حتى تستطيع إحداث لون التتمية المطلوبة.

جدول (1)

توزيع عينة الدراسة تبعا لمتغيرات الدراسة

\begin{tabular}{|c|c|c|c|}
\hline النسبة & العينة & & متغيرات الدراسة \\
\hline$r \uparrow, Y$ & $\wedge$. & الذكور & \multirow{2}{*}{ النوع } \\
\hline$V r, r$ & rr. & الإناث & \\
\hline$v$. & rl. & ذات طبيعة نظرية & \multirow{2}{*}{ الكلية } \\
\hline$r$. & 9. & ذات طبيعة عملية & \\
\hline$r, Y$ & 41 & أقل من خمس سنوات & \multirow{4}{*}{ الخبرة } \\
\hline$\varepsilon r$ & 149 & من ه إلى · ل سنوات & \\
\hline 17 & $\varepsilon \wedge$ & من 11 إلى 10 سنة & \\
\hline $1 \wedge, r$ & 00 & أكثر من 10 سنة & \\
\hline$v, r$ & rr & معيد & \multirow{5}{*}{ الدرجة العلمية } \\
\hline$I V, r$ & or & محاضر & \\
\hline $0 \wedge, r$ & 1vo & أستاذ مساعد & \\
\hline $1 \leqslant, \varepsilon$ & $\varepsilon r$ & أستاذ مشارك & \\
\hline$r, V$ & $\wedge$ & أستاذ دكتور & \\
\hline $1 \ldots$ & r... & \multicolumn{2}{|c|}{ الإجمالي } \\
\hline
\end{tabular}

ו- معرفة استجابات عينة الدراسة تجاه درجة تواجد أهداف الدراسة الميدانية: تهدف الدراسة الميدانية إلى الإجابة على التساؤلات متطلبات هندرة العمليات الإدارية والأكاديمة. 
• لا توجد فروق ذات دلالة إحصائية بين استجابات

عينة الدراسة على تعزى إلى الخبرة. أدوات الدراسة الميدانية وخطوات إعدادها:

لتحقيق الهدف من الدراسـة الميدانيـة تم تصـيم استبانة موجهة إلى أعضاء هيئة التدريس من الذكور

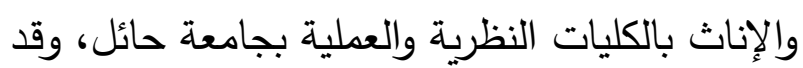
مرت هذه الاستبانة بالمراحل التالية:

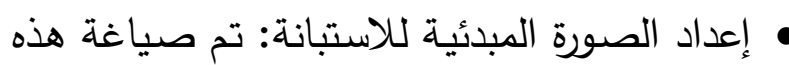
الصورة وتتظيم محاورها بالاستعانة بالدراسات السابقة

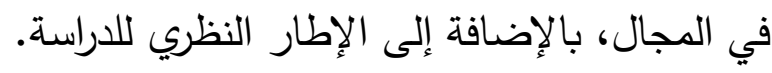

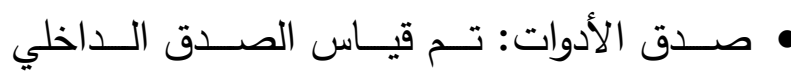
للاستبانة من خلال ما يلي:

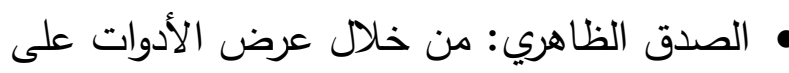

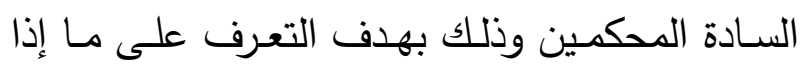
كانت تلك الأدوات تقيس مـا وضـعت لقياسـه أم لا، وقد أسفر التحكيم عن وجود تعديلات داخل عبارات

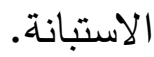

ه الصدق الداخلي: وذلك من خـلال معامل ارتباط

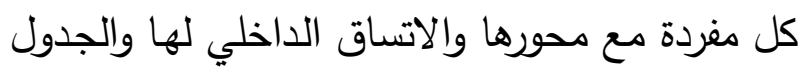
التالي يوضح ذلك: r- هـل هنـاك فـروق ذات دلالــة إحصـائية بـين

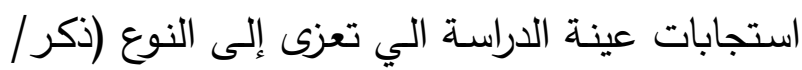
أنثى) r- هـل هنـاك فـروق ذات دلالــة إحصــائية بـين اسـتجابات عينـة الدراســة على تعـزى إلـى الكليـة (نظرية/عملية)؟

ع- هـل هنــالك فـروق ذات دلالــة إحصـائية بـين اسـتجابات عينـة الدراسـة على تعـزى إلـى الدرجـة الدهـ

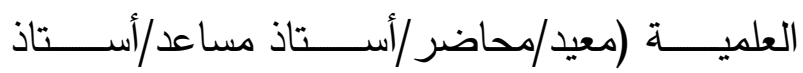
مشارك/أستاذ دكتور )؟

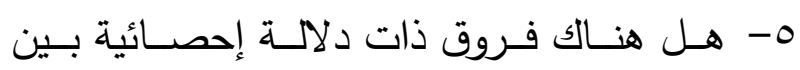
استجابات عينة الدراسة على تعزى إلى الخبرة؟ فروض الدراسة: لا توجد فروق ذات دلالة إحصائية بين استجابات عينة الدراسة الي تعزى إلى النوع (ذكر / أنثى). لا توجد فروق ذات دلالة إحصائية بين استجابات عينة الدراسة على تعزى إلى الكلية (نظرية/عملية). لا توجد فروق ذات دلالة إحصائية بين استجابات عينــة الدراســة علـى تعـزى إلـى الدرجـة العلميــة

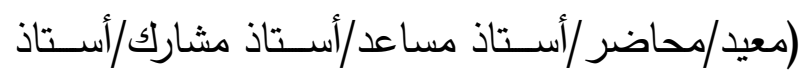
دكتور) 


\section{جدول (r)}

جدول يبين معامل ارتباط كل مفردة مع محورها

\begin{tabular}{|c|c|c|c|c|c|c|c|}
\hline \multicolumn{4}{|c|}{ المحور الثاني } & \multicolumn{4}{|c|}{ المحور الأول } \\
\hline معامل الارتباط & السؤال & معامل الارتباط & السؤال & معامل الارتباط & السؤال & معامل الارتباط & السؤال \\
\hline$* *,, \vee \varepsilon$ & Vqu & $* *,, \leqslant 9$ & س & $* *, 7 \leq$ & س rv & $* *, 01$ & س \\
\hline$* *, \vee \wedge \wedge$ & س. & $* *,, 7 \leq$ & سع & $* *, \vee \vee \succ$ & سمب & $* *,, \vee \wedge$ & سץ \\
\hline$* *, \wedge$. & س & $* *, 0 \leq$ & س & $* *, \vee \vee\urcorner$ & س99r & $* *, 79$ & س \\
\hline$* *, \vee$, & سro & $* *$, ov & س 07 & $* *, \wedge$. & س.r & $* *,, \vee 0$ & س ع \\
\hline$* *,, \vee \wedge$ & س سمر & $* *, 77$ & س ov & $* *,, v 1$ & س اب & $* *, \vee \vee\urcorner$ & سن \\
\hline$* *, \vee \vee \wedge$ & سع & ** ש & سNo & $* *, \wedge 1$ & س rr & $* *, \vee \vee$ & س \\
\hline$* *, \wedge 1$ & Now & $* *, 77$ & س 09 & $* *, \mathrm{VV}$ & س سז & $* *, v \leq$ & س V \\
\hline$* *, \wedge r$ & س سזم & $* *,, V r$ & س. & $* *, \wedge$. & س ع & $* *, 7 V$ & سمر \\
\hline$* *, 7 V$ & N س & $* *, 71$ & س ال & $* *,, v r$ & س مr & $* * \cdot, V r$ & سو9 \\
\hline$* *, 7 V$ & Nیw & $* *, 70$ & س & $* *, \wedge$ & س צr & $* *, 79$ & س. \\
\hline$* *, V r$ & س & $* *, \wedge)$ & س & $* *, \vee V$ & س Vr & $* *$, or & س \\
\hline$* *,, V I$ & a.w & $* *, \vee \vee$ & س 17 & $* *, 0 \wedge$ & سمץ & $* *, 79$ & س \\
\hline \multirow[t]{14}{*}{$* *, \vee v 1$} & س 99 & $* *, 7 \wedge$ & س 70 & $* *,, V V$ & س وr & $* *,, \leq 0$ & س \\
\hline & & $* *$ * or & سדו & $* *, 7 \wedge$ & س. & $* *,, \vee \wedge$ & س 1 \\
\hline & & $* *, \wedge$ & س TVT & $* *, \wedge r$ & س إع & $* *, \vee \vee$ & س 10 \\
\hline & & $* *,, V r$ & س11 & $* *, \wedge r$ & س & $* *, T r$ & س 17 \\
\hline & & $* *, V Y$ & س997 & $* *, \vee \vee\urcorner$ & س & $* *, 79$ & س VI \\
\hline & & $* *,, \vee V$ & v.w & $* *, 07$ & س ع & $* *, \wedge 1$ & سم| \\
\hline & & $* *, \vee \vee 9$ & س VI & $* *, \wedge r$ & س & $* *,, 7 \wedge$ & س 19 \\
\hline & & $* *, \vee \vee\urcorner$ & س VY & $* *, \wedge 1$ & س & $* *, \leq 9$ & س.r \\
\hline & & $* *,, 7 \wedge$ & س V & $* *, \wedge$. & س & $* *,, \uparrow \wedge$ & س اب \\
\hline & & $* *, 77$ & س & $* *, \vee \vee \leq$ & س & $* *,, \leq \leq$ & س rr \\
\hline & & $* *, \wedge)$ & س vo & $* *$, , $>0$ & ـ & $* *, \Gamma \wedge$ & س \\
\hline & & $* *, \wedge$ & سTV & $* *, \vee \vee q$ & س. & $* *, 09$ & س ع \\
\hline & & $* *, \wedge 1$ & س VV & $* *, V$. & س 01 & $* *,, V I$ & س r \\
\hline & & $* *, \wedge)$ & سN & $* *, 7 \mathrm{~V}$ & س or & $* *$, Tr & س דr \\
\hline
\end{tabular}

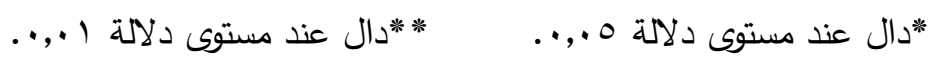

وبقراءة جدول السابق يتبين وجود ارتباط قوي موجب يـدل على وجود اتسـاق داخلي كبير بين مفردات عند مستوى دلالة ا, · بين كل مفردة في المحور في الاستبانة.

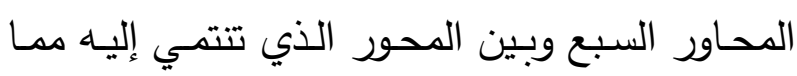


حصـلت الاسـتبانة على نفس درجـة الثبـات في هي

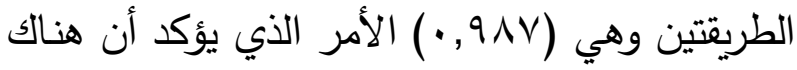

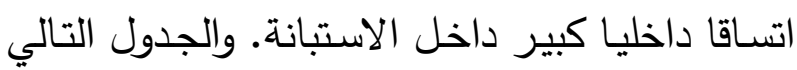
يبين ذلك

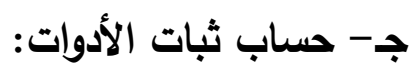

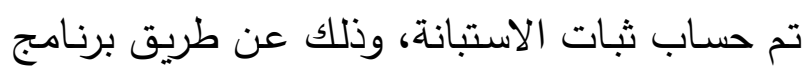

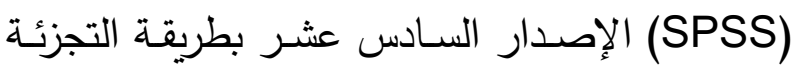

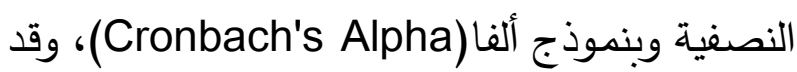

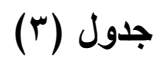

نسبة ثبات الاستبانة بطريقة الفا كرونباح

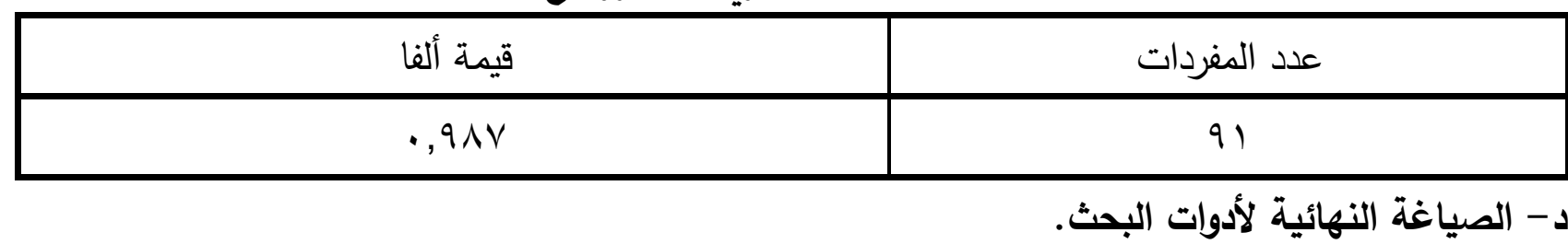

بعد الانتهاء من المراحل السابقة تم صياغة الاستبانة بصورة نهائية وذلك على النحو المبين بالجدول التالي:

جدول (؛)

توزيع العبارات على محاور الاستبانة قبل التعديل وبعده

\begin{tabular}{|c|c|c|c|}
\hline الإجمالي بعد التعديل & الإجمالي قبل التعديل & محاور الاستبانة & s \\
\hline & & الدحور الأول: متطلبات هندرة العمليات الإدارية: & .1 \\
\hline$\varepsilon$ & 0 & | أولا: رؤية ورسالة الجامعة وأهدافها & .4 \\
\hline 7 & 0 & | ثانيا: تتمية القدرات & r \\
\hline 9 & 9 & 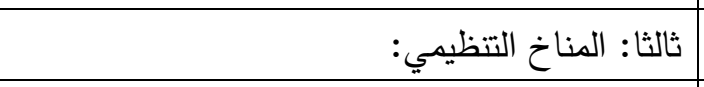 &.$\varepsilon$ \\
\hline ir & ir & | رابعا: الموقع الإلكتروني للجامعة: & .0 \\
\hline ir & ir & خامسا: خدمة الدجتمع والعلاقات الدولية: & .7 \\
\hline \multirow[t]{3}{*}{9} & 1. & | سادسا: التقويم: &.$\vee$ \\
\hline & & المحور الثاني: متطلبات هندرة العمليات الأكاديمية: &.$\wedge$ \\
\hline & & | أولا: التتربس والتعليم: & .9 \\
\hline 7 & $\wedge$ & |أ. كفاءة الطلاب: & .1 . \\
\hline 0 & 1 & |ب.كفاءة أعضاء هيئة التدريس: & .11 \\
\hline 7 & 7 & ت. التكنولوجيا في حجرة الدراسة: & .14 \\
\hline $\mathrm{v}$ & 7 & |ثانيا: تصميم المناهج: & .11 \\
\hline 10 & $1 \varepsilon$ & | ثالثا: البحث العلمي: & $.1 \varepsilon$ \\
\hline 91 & $9 \pi$ & | المجموع الكلي للعبارات & \\
\hline
\end{tabular}


حسـاب دلالــة الفـروق بـين المتوسـطات لمتغيـر

الدرجة العلمية والخبرة عن طريق اختبار ف أنوفا. • اختبار توكي لمعرفة اتجاه دلالة الفروق في حالة

وجود دلالة بين المتغيرات.

هساب المتوسط المرجح بالأوزان النسبية لمعرفة

ترتيب العبارات في كل محور من قبل عينة الدراسة.

نتائج الدراسة الميدانية وتفسيرها:

أولا: فيما يتعلق بالإحابة عن السؤال الأول:

جاءت نتائج الإجابـة على السؤال الأول على النحو

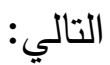

أسفرت نتائج الدراسة عما يلي:

جدول (0)

نتائج الدراسة الميدانية فيما يتعلق برأي عينة الدراسة

\begin{tabular}{|c|c|c|c|c|c|}
\hline 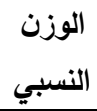 & غوافق & 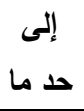 & 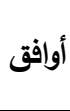 & 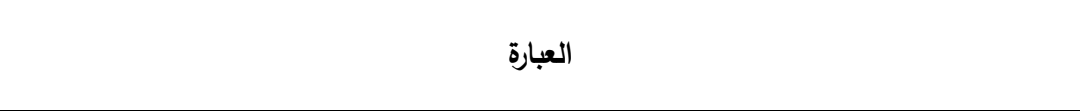 & \\
\hline & & & & المحور الأول: متطلبات إعادة هندسة العمليات الإدارية: & .1 \\
\hline & & & & أولا: رؤية ورسالة الجامعة وأهدافها: &.$r$ \\
\hline 40.67 & 159 & $v \wedge$ & Ar & شاركت في صياغة رؤية ورسالة الجامعة. &.$r$ \\
\hline 59.83 & Ar & V & $1 \leqslant 1$ & أرى رؤية ورسالة الجامعة معلقة في مكان بارز به ليشهذها الجميع. &.$\varepsilon$ \\
\hline 75.33 & r人 & vr & 19. & تم اعتماد رؤية ورسالة الجامعة من مجلس الإدارة. & .0 \\
\hline 77.83 & rq & 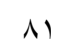 & 194 & رؤية ورسالة الجامعة متفقة مع المبادئ العلمية لصياغتها (مختصرة/طموحة/ مميزة للمؤسسة...). & .7 \\
\hline \multirow[t]{2}{*}{63.42} & & & & المتوسط & \\
\hline & & & & 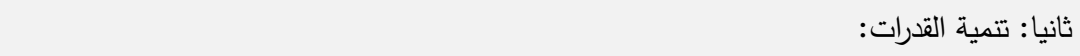 & \\
\hline 67.83 & ov & vq & $17 \varepsilon$ & يوجد لاى الجامعة وحدة لتتمية قدرات أعضاء هيئة التدريس بالجامعة. & $\cdot v$ \\
\hline 63.17 & TV & AV & $1 \leq 7$ & البحثية بثكل دوري. آستلاء أعضاء هيئة التدريس في الدورات التدريبية التي يمكن أن تسهم في رفع قدراتهم & .1 \\
\hline 55.33 & V7 & 117 & $1 \cdot 1$ & يتم تلبية احتياجات أعضاء هيئة التدريس الدورية من الدورات التدريبية التي يحتاجونها بشكل سريع. & .9 \\
\hline 37.33 & $1 \leqslant r$ & qr & 77 & كل تخم عمل سيمينار دوري معلن عنه يحضره أحد كبار المتخصصين لإلقاء محاضرة عن الجديد في & .1 . \\
\hline 38.33 & 114 & 91 & 77 & يتم تقييم مدى الاستفادة من تلك السمينارات بشكل دوري والاستجابة للملاحظات التي يبديها أعضاء & .11 \\
\hline
\end{tabular}

الأسـلوب الإحصــائي المسـتخدم: تمــ الاسـتعانة ببرنـامج الحزم الإحصـائية الـ ( SPSS) الإصـدار السادس عشر ، وقد تم استخدام الأسـاليب الإحصائية

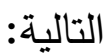
• معامل الاتباط لقياس الصدق الداخلي للاستبانة، ومعامل ارتباط كل مغرده بمحورها. •مـوذج ألـف كرونبــاح لقيـاس ثبـات الاسـتبانة. والتكرارات والنسب المئوية. هــاب دلالــة الفـروق بـين المتوسـطات لمتغيـر النوع وطبيعة الكلية عن طريق اختبار ت. 
" متطلبات تطبيق هندرة الجامعات السعودية في ضوء تحديات العصر الرقمي"

\begin{tabular}{|c|c|c|c|c|c|}
\hline 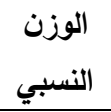 & غوافق & 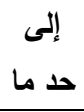 & أوافق & 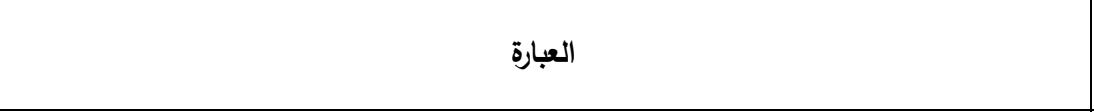 & \\
\hline & & & & هيئة التدريس. & \\
\hline 41.67 & 14 & $\wedge \wedge$ & $\wedge$ & 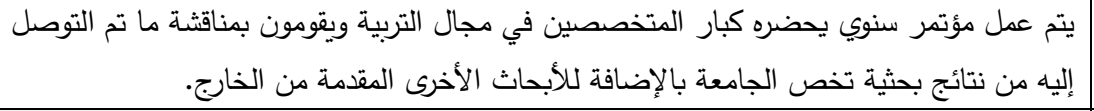 & .14 \\
\hline \multirow[t]{2}{*}{50.61} & & & & المتوسط & \\
\hline & & & & | ثالثا: المناخ التتظيمي: & \\
\hline 85.50 & $1 \leqslant$ & 09 & rtr & لا أتعامل إلا مع رئيسي المباشر فقط، ولا أتخطى الهيكل التظظمي. & .14 \\
\hline 50.83 & $1 \cdot v$ & ᄉ & $11 r$ & قتت باستلام توصيف وظيفي للمهام المطوبة مني فور استلامي العمل. & $.1 \leq$ \\
\hline 84.83 & iv & ov & rYt & | يتعامل رئيسي المباشر معي باحترام وبمرونة. & .10 \\
\hline 68.50 & 0. & 19 & 171 & تثجع القيادات الإدارية و الفنية على العمل بروح الفريق و التعاون. & .17 \\
\hline 72.83 & r. & $1 . r$ & $17 \mathrm{~V}$ & يسير العمل في غياب المدير بكفاءة لتفويضه مهامه لنائبه في حالة غيابه. & $.1 \mathrm{~V}$ \\
\hline 67.33 & 07 & $\wedge \varepsilon$ & 17. & | أشعر بتقدير واستجابة لأي مبادرة تطوير أقدمها لرئيسي في العمل. & .11 \\
\hline 70.67 & re & $1 \cdot r$ & 171 & | يتم الإعلان عن القرارات الهامة التي تتخذها الإدارة العليا. & .19 \\
\hline 45.67 & 111 & 9 . & 94 & | أشارك في وضع الخطط الاستراتيجية للجامعة. & .r. \\
\hline 45.83 & 149 & TV & $1 \cdot \varepsilon$ & شاركت في تتفيذ الخطة الإستراتيجية للجامعة ووضع الخطط التتفيذية المصاحبة لها. & .4 \\
\hline \multirow[t]{2}{*}{65.78} & & & & المتوسط & \\
\hline & & & & | رابعا: الموقع الإكتروني للجامعة: & \\
\hline 86.00 & 10 & $0 \leqslant$ & rm & | يوجد موقع إلكتروني محدث للجامعة. & rt \\
\hline 69.67 & rq & Irs & $1 \leq V$ & تنشر جميع القرارات واللوائح والقوانين المنظمة للجامعة على الموقع. & r \\
\hline 91.17 & $\wedge$ & ri & roo & | يشتمل الموقع على رؤية ورسالة الجامعة. & $. r \leqslant$ \\
\hline 90.50 & 10 & rV & roN & | لغة الموقع الإكتروني للجامعة هي العربية والإنجليزية معا. &.$r_{0}$ \\
\hline 69.83 & or & $\checkmark v$ & $|v|$ & | يوجد مكتبة إلكترونية تشتمل على جميع الأبحاث التي يقدمها الجامعة. & צד \\
\hline 52.67 & 9. & $1 \cdot \varepsilon$ & 1.7 & يوجد مكتبة برامج تشتمل على البرامج الهامة لهم كبرنامج ال SPSS Sوبرنامج السرقات العلمية. &.$r V$ \\
\hline 70.50 & $\leq 7$ & 10 & 179 & يتم التعامل بين الأقسام والكليات من خلال البريد الإكتروني الرسمي لهم على موقع الجامعة. & $.4 \Lambda$ \\
\hline 68.17 & $\varepsilon \wedge$ & 90 & $10 \mathrm{~V}$ & |توجد قاعدة بيانات بجميع أعضاء هيئة التدريس بالجامعة وسيرتهم الذاتية على الموقع. & .49 \\
\hline 62.00 & 79 & 97 & $1 \mathrm{r}$ & توجد خطة إستراتيجية للجامعة على الموقع الرسمي لهم. &.$r$. \\
\hline 67.83 & Tr & 79 & 179 & | يوجد دليل رسمي للجامعة على موقعه. &.$\mu$ \\
\hline 55.33 & м & 94 & ir. & | تنشر الجامعة التقارير الدورية لها على الموقع الرسمي. & rt \\
\hline 54.50 & 97 & 1) & Irt & المستفيدين منها. & r \\
\hline \multirow[t]{2}{*}{69.85} & & & & المتوسط & \\
\hline & & & & | خامسا: خدمة المجتمع والعلاقات الدولية: & \\
\hline 60.83 & 79 & $9 \vee$ & $1 \pi \leq$ & | تقدم الجامعة خدمة الاستشارات والدعم للمجتمع. &.$r \varepsilon$ \\
\hline 64.17 & $\leq 7$ & Irr & 14 & | تقوم الجامعة بعمل مشروعات تخدم المجتمع. & ro \\
\hline 53.33 & Ar & 117 & $1 . r$ & تقوم الجامعة بتقديم خدمات الاستشارات والدعم لأنظمة تعليمية أخرى بالخارج. & ד \\
\hline
\end{tabular}




\begin{tabular}{|c|c|c|c|c|c|}
\hline 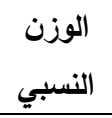 & غوافق & 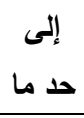 & أوافق & 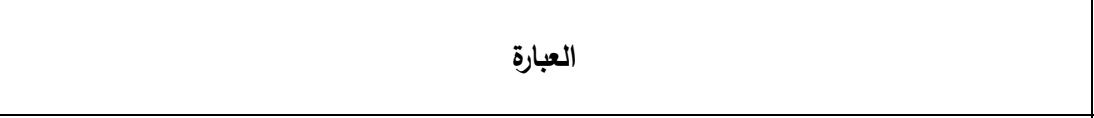 & \\
\hline 66.83 & $\leq 7$ & $1 \cdot \mathrm{V}$ & $1 \leqslant v$ & | تعقد الجامعة اتفاقيات تعاون وشراكة مع الجامعات المتقدمة عالميا. &.$r v$ \\
\hline 59.00 & $\checkmark \cdot$ & 1.7 & $M \leq$ & | تقدم الجامعة برامج بالتعاون مع جامعات عالمية أجنبية معتمدة. & .r人 \\
\hline 61.00 & Tr & $11 \cdot$ & IrA & تتعاون الجامعة مع الجامعات السعودي الأخرى لخدمة المتمع. & .49 \\
\hline 58.17 & 90 & 7 & $1 \leq \varepsilon$ & ترسل الجامعة أعضاء هيئة تدريس في مهام علمية وبعثات للدول المتقدمة للاستفادة من خبراتهم. &.$\varepsilon$. \\
\hline 52.83 & $\mathrm{VT}$ & 14 & qr & تعقد الجامعة اتفاقيات دولية مع مراكز البحوث العالمية بالخارج لتحقيق التعاون العلمي المشترك. &.$\leqslant 1$ \\
\hline 63.50 & $\mathrm{v}$. & $\mathrm{vq}$ & 101 & تقدم الجامعة منحا تدريسية للباحثين من داخل المملكة وخارجها. &.$\varepsilon r$ \\
\hline 44.33 & $11 \mathrm{~V}$ & $1 \ldots$ & $\wedge r$ & من خارج الجامعة. &.$\varepsilon r$ \\
\hline 59.33 & Vr & 91 & 149 & تقدم الجامعة الخدمات الاستثارية التي يحتاج إليها القيادات العليا. &.$\varepsilon \varepsilon$ \\
\hline 42.17 & $1 r \varepsilon$ & 99 & VV & الجامعة. . تجدم الجامعة خدمـة الترجمـة المتخصصـة والمراجعـة اللغويـة والنشـر الدولي للبـاحثين مـن خـارج &.$\leqslant 0$ \\
\hline 57.13 & & & & 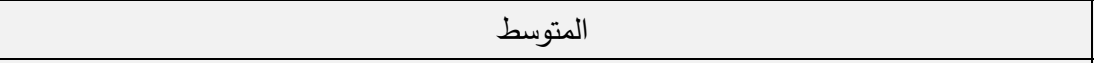 & \\
\hline & & & & | إدسا: التقويم: & \\
\hline 86.50 & 10 & 01 & $r r \leq$ & يتم استطلاع رأي الطلاب في أعضاء هيئة التدريس. &.$\leqslant 7$ \\
\hline 63.00 & 70 & 94 & $1 \leq r$ & يتم استطلاع رأي أعضاء هيئة التدريس في الخدمات المقدمة لهم لتطويرها. &.$\leqslant V$ \\
\hline 52.17 & $1 \cdot r$ & $\wedge r$ & 110 & يتم استطلاع رأيي في الخدمات المقدمة من الدكتبة. &.$\leqslant \wedge$ \\
\hline 53.00 & $1 . r$ & $\mathrm{vA}$ & ir. & يتم استطلاع رأيي في الخدمات المقدمة من الهئية الإدارية. &.$\leqslant 9$ \\
\hline 45.83 & 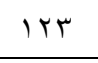 & vq & 91 & يتم استطلاع رأيي في أداء عمال النظافة. & .0 . \\
\hline 55.50 & 97 & vo & 149 & أشعر بمردود إيجابي على ما أبديه من ملاحظات بعد أخذ رأيي. & .01 \\
\hline 54.00 & 90 & 14 & 119 & يتم توفير جميع ما أطلبه من احتياجات تدريسية للعمل سنويا. & .04 \\
\hline 62.00 & 0. & IYN & Irr & يتم إصلاح أي عطل يحدث في أجهزة الجامعة بشكل سريع. & .04 \\
\hline 41.67 & 147 & 91 & $v_{7}$ & يتم استطلاع رأيي في أداء رؤسائي في العمل. & $.0 \leqslant$ \\
\hline 57.07 & & & & المتوسط & \\
\hline \multicolumn{4}{|c|}{60.64} & إجمالي متوسط المحور الأول & \\
\hline & & & & المحور الثاني: متطلبات إعادة هندسة العمليات الأكاديمية: & \\
\hline & & & & | أولا: التدريس والتعليم: & \\
\hline & & & & ث. كفاءة الطلاب: & \\
\hline 67.83 & 19 & 100 & Iry & | تقل نسبة رسوب الطلاب/ الطالبات سنويا. & .00 \\
\hline 67.33 & r & 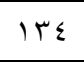 & ho & تقل نسبة التسرب بين الطلاب/ الطالبات سنويا. & .07 \\
\hline 66.83 & ra & $|r|$ & $1 \varepsilon$ & ترتفع المعدلات الأكاديمية للطلاب سنويا. & $.0 \mathrm{~V}$ \\
\hline 69.50 & $\varepsilon r$ & 99 & 109 & يتزايد اقبال الطلاب على استكمال دراستهم العليا بشكل كبير. & .01 \\
\hline 48.17 & VV & $10 \mathrm{~V}$ & 74 & يتردد الطلاب كثيرا على المكتبات لإنجاز أبحاثهم. & .09 \\
\hline 48.50 & Ar & $1 \leqslant r$ & $v \varepsilon$ & يلتحق أكثر الطلاب بسوق العمل بعد تخرجهم. & .7. \\
\hline 61.36 & & & & المتوسط & \\
\hline
\end{tabular}


" متطلبات تطبيق هندرة الجامعات السعودية في ضوء تحديات العصر الرقمي"

\begin{tabular}{|c|c|c|c|c|c|}
\hline 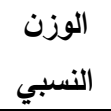 & موافق & 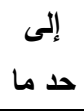 & أوافق & 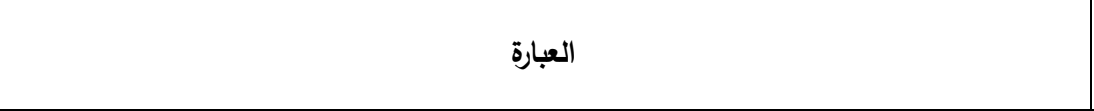 & \\
\hline & & & & ج. كفاءة أعضاء هيئة التدريس: & \\
\hline 68.33 & $r \leq$ & Irt & $1 \leq \varepsilon$ & | يراعى التخصص العلمي في تدريس البرامج الأكاديمية بشكل دقيق. & .71 \\
\hline 55.00 & (1) & irs & $1 \cdot 1$ & يجري أعضاء هيئة التدريس بحثا واحدا سنويا على الأقل في مجال تخصصهم لمواكبة الجديد. & .44 \\
\hline 74.00 & rr & $11 \mathrm{r}$ & 177 & | يقوم أعضاء هيئة التدريس بنشر أبحاثه في مجلات علمية محكمة. & .4 \\
\hline 74.83 & ry & 99 & ivo & | يتفاعل أعضاء هيئة التدريس مع طلابهم عبر الوسائل الإلكترونية بشكل جيد. & $.7 \varepsilon$ \\
\hline 73.17 & rq & 1.9 & 170 & | يستخدم أعضاء هيئة التدريس التكنولوجيا في العملية التدريسية بكفاءة عالية. & .70 \\
\hline \multirow[t]{2}{*}{69.07} & & & & المتوسط & \\
\hline & & & & | ح. التكنولوجيا في حجرة الدراسة: & \\
\hline 67.17 & r & iro & $1 \pi \varepsilon$ & | يوجد قاعات تدريسية مزودة بأجهزة عرض مناسبة. & .74 \\
\hline 58.33 & vo & $1 \cdots$ & iro & يوجد انترنت موصل بالقاعات التدريسية لاستخدامة في العملية التدريسية. & $.7 \mathrm{~V}$ \\
\hline 46.17 & 11. & $1 . r$ & $\wedge \vee$ & | يوجد سبورات ذكية بالقاعات التدريسية. & .71 \\
\hline 63.83 & $r v$ & $1 \leqslant r$ & ir. & | يستخدم أعضاء هيئة التدريس الوسائل التكنولوجية أثناء التدريس. & .79 \\
\hline 55.50 & VA & 111 & 111 & تم تدريب أعضاء هيئة التدريس على كيفية استخدام الوسائط التكنولوجية الموجودة بالقاعات. &.$\vee$. \\
\hline 57.67 & TV & ir. & $11 \pi$ & | يوجد دعم فني جيد للقاعات لإصلاح أي عطل يطرأ داخل القاعات. &.$v 1$ \\
\hline \multirow[t]{2}{*}{58.11} & & & & المتوسط & \\
\hline & & & & 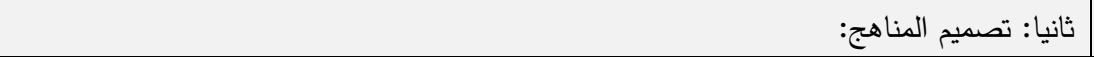 & \\
\hline 63.67 & 纟o & ir & irv & | مواصفات المقررات ملائمة للتطورات التكنولوجية الحديثة. &.$V r$ \\
\hline 64.17 & or & 111 & irv & | يتم تحديث مواصفات المقررات التدريسية كل خمس سنوات على الأقل. &.$V T$ \\
\hline 67.50 & rq & $1 \mathrm{ir}$ & $1 T \varepsilon$ & | لتيم الرجوع إلى المراجع الحديثة في التدريس. &.$v \varepsilon$ \\
\hline 51.50 & v9 & irr & $\wedge 1$ & يتم تصميم مقررات تفاعلية على موقع الجامعة لكل مقرر تدريسي. &. $\mathrm{V}^{\circ}$ \\
\hline 43.50 & $1 . r$ & 1ro & זי & | يتم عمل حقائب تكنولوجية إلكترونية لكل مقرر للمسجلين بالمقرر من بعد. &.$\vee 7$ \\
\hline 60.33 & 79 & $1 \cdots$ & $1 \mathrm{~m}$ & يتم أخذ ملاحظات أعضاء هيئة التدريس سنويا على كل مقرر لتحديثه. &.$V V$ \\
\hline 65.83 & or & $1 \cdot 1$ & $1 \leq v$ & يتم أخذ ملاحظات الطلاب سنويا على كل مقرر لتحديثه. &.$\vee \wedge$ \\
\hline \multirow[t]{2}{*}{59.50} & & & & 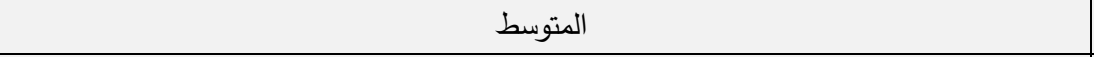 & \\
\hline & & & & 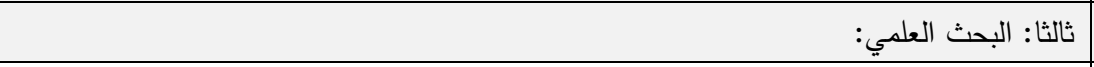 & \\
\hline 55.67 & vr & Irr & 1.7 & توجد بالجامعة خطة بحثية محددة و معلنة للجميع تتتاسب مع طبيعة المؤسسة ورسالتها &.$\vee 9$ \\
\hline 52.83 & $\wedge$. & irr & $9 \vee$ & يتم تتفيذ الخطة الموضوعه للجامعة بدقة وبنجاح. &.$\wedge$. \\
\hline 42.33 & iro & 97 & $\vee q$ & والتحليل الإحصائي المناسب لهاليا بوحدة إحصائي تقوم بالاختيار الصحيح لعينة البحث الممثلة للأصل الكلي &.$\wedge 1$ \\
\hline 50.83 & $1 . r$ & 91 & $1 \cdot v$ & | تخصص الجامعة ميزانية كافية تمكنها من تحقيق خطتها البحثية. &.$\wedge r$ \\
\hline 53.17 & $\Lambda \mathrm{V}$ & $1 \cdot v$ & 1.7 & | يوجد آليه تضمن صدق وفاعلية التطبيق الميداني. &.$\wedge r$ \\
\hline 54.50 & Vr & 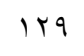 & 99 & يوجد تحكيم للأبحاث العلمية من خبراء في التخصص خارج الجامعة بعد الانتهاء منها. &.$\wedge \varepsilon$ \\
\hline 61.50 & 10 & $1 \cdot 1$ & $1 r \varepsilon$ & |تتوافر للى الجامعة سياسات لحماية حقوق الملكية الفكرية. & .10 \\
\hline 61.17 & $T \varepsilon$ & 1.0 & $1 \pi$ & ت تنشر الأبحاث التي يقدمها الجامعة في مجلة علمية محكمة معتمدة دوليا. &.$\wedge 7$ \\
\hline
\end{tabular}




\begin{tabular}{|c|c|c|c|c|c|}
\hline النوزن & غير & حد مالى & أوافق & 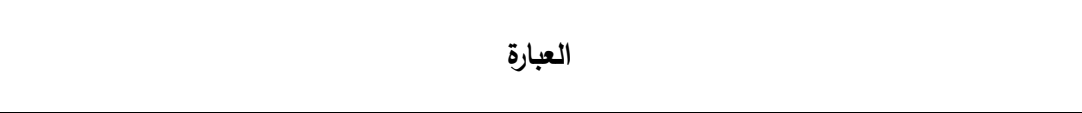 & \\
\hline 45.00 & 11. & 11. & $\wedge$. & تلتوفر للجامعة ميزانية كافية لتمويل البرامج وقواعد البيانات والأجهزة الضرورية لإجراء البحث &.$\wedge V$ \\
\hline 52.50 & $1 \cdots$ & 1० & 110 & توجد آلية للتطوير المستمر لخدمات المكتبة بما يدعم احتياجات التدريس والبحث العلمي. &.$\wedge \wedge$ \\
\hline 67.17 & T4 & $v r$ & 170 & توجد قواعد بيانات إلكترونية تشتمل على المراجع والمجلات العلمية التي تقدمها الجامعة سهل &.$\wedge 9$ \\
\hline 65.50 & 71 & 10 & $10 \leqslant$ & تقوم الجامعة بتوفير خدمات الإنترنت والاستعارة من المكتبة. & .9. \\
\hline 34.17 & $10 \mathrm{~V}$ & $\Lambda$ & Tr & يوجد بالجامعة وحدة ترجمة متخصصة لترجمة الأبحاث للغة الإنجليزية. & .91 \\
\hline 33.50 & $17 \varepsilon$ & ( & 70 & يوجد بالجامعة وحدة للمراجعة اللغوية للأبحاث. & .94 \\
\hline 41.00 & 149 & $v$ & 10 & يوجد بالجامعة وحدة للنشر الدولي لها رابط بموقع الجامعة ومصنفة بقواعد البيانات العالمية & .94 \\
\hline 51.39 & & & & المتوسط & \\
\hline \multicolumn{4}{|c|}{59.89} & إجمالي متوسط المحور الثاني & \\
\hline \multicolumn{4}{|c|}{60.26} & إجمالي متوسط محاور الاستبانة & \\
\hline
\end{tabular}

حصل مؤشر كفاءة أعضاء هيئة التدريس على أعلى وزن نسبي من وجهة نظر عينـة الدارسة في المحور

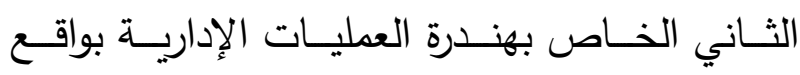

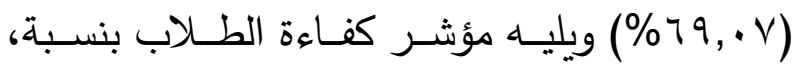

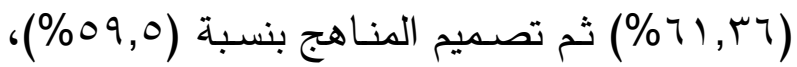

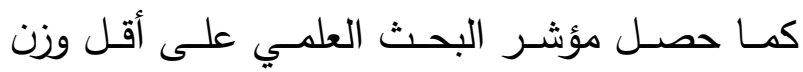

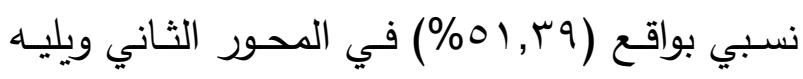

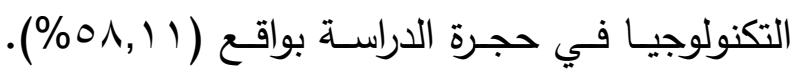
ومتوسط إجمالي المحور الثاني بلغ (9,190\%). بالنسبة لإجمالي محاور الاستبانتة: يعد متوسط الوزن النسبي للإجمالي العام للاستبانة

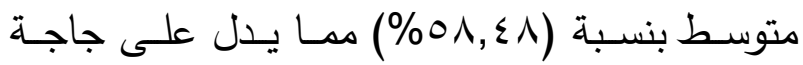

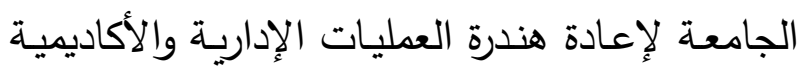
معـا، وتفـوق نسـبيا محسور متطلبـات إعـادة هندرة

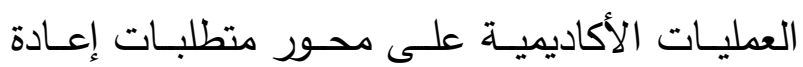

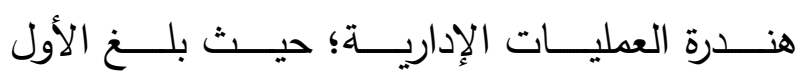

تبين قراءة الجدول (0) ما يلي:

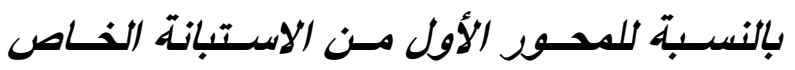
بتطلبات إعادة هندسة العمليات الإدارية: حصل مؤشر الموقع الآكتروني للجامعة على أعلى لهى وزن نسبي من وجهة نظر عينة الدارسة في المحور

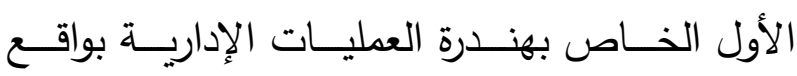

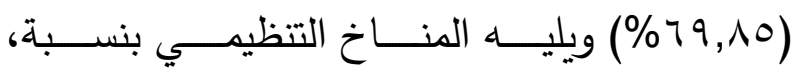
(\%70,V^)

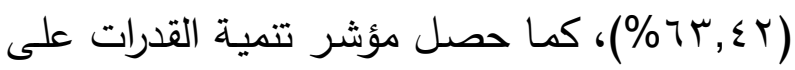
أقل وزن نسبي بواقع (آ, •0\%) في المحور الأول

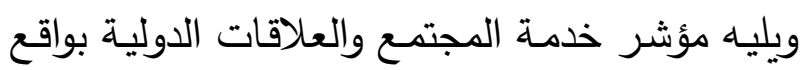

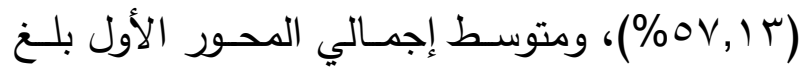
. $(\% \circ v, \cdot v)$ بالنسـبة للمدسور الثـانسي مسن الاسـتبانة النـاص بتطلبات إعادة هنسلة العمليات الأكاديية: 
الادراسـة (النـوع /وطبيعـة الكليـة والدرجـة العلميـة

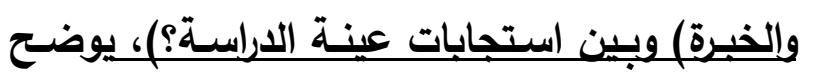
الجدول التالي ذلك الكين التين

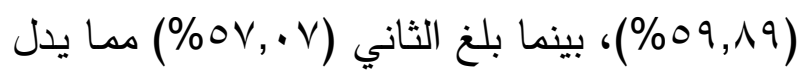

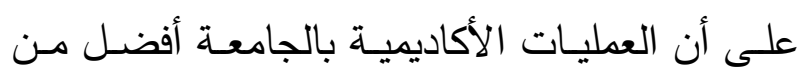
العمليات الإدارية.

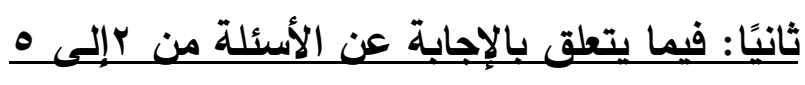

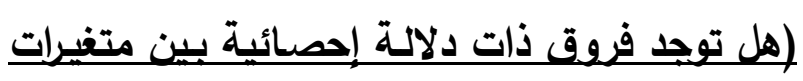

جدول (7)

دلالة الفروق بين الاستجابات ومتغيرات الدراسة

\begin{tabular}{|c|c|c|c|c|c|}
\hline \multicolumn{2}{|c|}{ اختبار (ت) } & \multicolumn{2}{|c|}{ اختبار أنوفا } & & \\
\hline طبيعة الكلية & النوع & الخبرة & الدرجة العلمية & & \\
\hline $1, V V$ & $r, \varepsilon$ & $* * 1 \cdot, r$ & $* * \mid r, 97$ & الإدارية الأحور الأول: متطلبـات إعادة هندسـة العمليـات & .1 \\
\hline T,Y & $* * 11, \cdot V$ & $* * \varepsilon, \wedge \Gamma$ & $* * \wedge, r q$ & الأكاديمية. الثاني: متطلبات إعادة هندسة العمليات &.$r$ \\
\hline$* T, v$. & $* 0, \wedge$ & $* * \wedge, r r$ & $* * 1, r, r$ & إجمالي محاور الاستبانة & r \\
\hline
\end{tabular}
"دال عند مستوى دلالة 0 .,...

إحصائية قوية عند مستوى (1 (.,.) بين متغير النوع

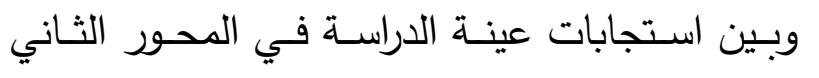

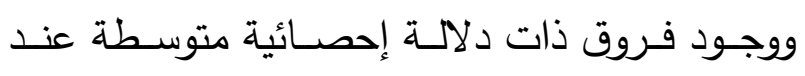

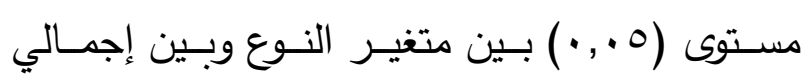

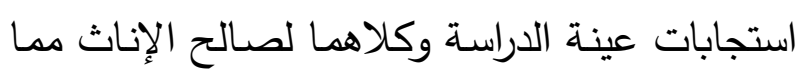
يدل على أن الإناث أكثر شعورا بأهميـة الهندرة في الإناث العمليـات الأكاديميـة من الذكور في عينـة الإراسـة.

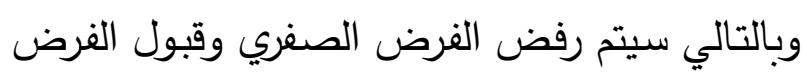

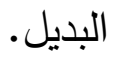

• لا توجد فروق ذات دلالة إحصائية بين استجابات

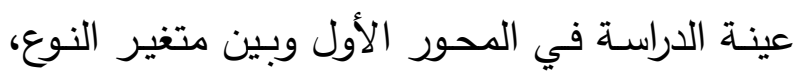

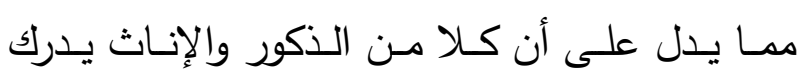

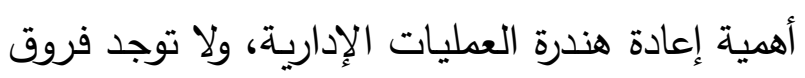

تبين قراءة الجدول (؟) ما يلي: • وجود فروق ذات دلالة إحصائية قوية عند مستوى دلئ

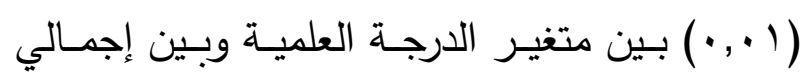

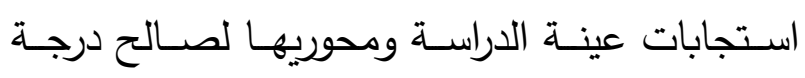
أستاذ مساعد مما يدل على أن الأسـاتذة المساعدين

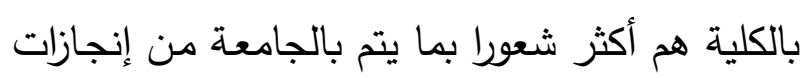

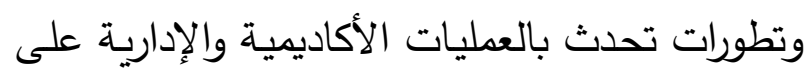
حد سواء، ووجود فروق ذات دلالـة إحصـائية قويـة عند مستوى (1 +., ·) بين متغير الخبرة وبين إجمالي

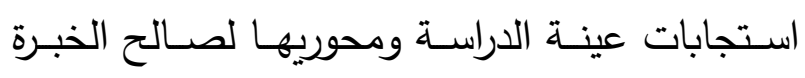

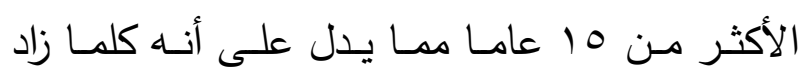

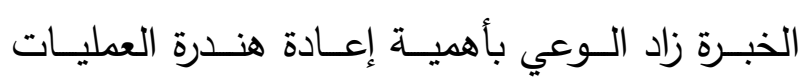

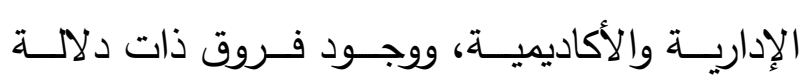


• وضع معايير لتعيين الأكفاء، وقياس الاحتياجات التقنية والفنية لأعضاء هيئة التدري، وفتح مجال الابتعاث، وتطوير المكتبات الجامعية، وقياس رضا جميع منسوبي الجامعة عن جميع الخدمات المقدمة من الجامعة، وتفعيل دور الجامعة في خدمة المجتمع. • تخفيف العبه الإداري عن أعضاء هيئة التدريس ليتاح لهم فرض البحث العلمي والتدري بشكل أفضل، وتطوير المقررات وتشجيع الطلاب على التعلم الذاتي والإبداع، وإتاحة فرص أكبر للمشاركة في المؤتمرات العالمية، وتطبيق مبدأ الثفافية الإدارية.

ومن الملاحظ أن جميع ما ذكره أعضاء هيئة التدرس من عينة الدراسة قد تم ذكره في الاستبانة، إلا أن تكراره يؤكد على أهميته بالنسبة لأعضاء هيئة التدريس. أهم توصيات الاراسة: من خلال ما توصلت إليه الدراسة من توجهات عالمية، ودراسة للواقع الجامعي توصلت الدراسة إلى عدد من التوصيات مقسمة على محورين هما: المحور الأول: متطلبات إعادة هندسة العملية الإداربـة: رؤية ورسالة الجامعة وأهدافها: مشاركة منسوبي الجامعة في صياغة رؤية ورسالة الجامعة بشكل علمي صحيح، وتعليقها في مكان بارز ، واعتمادها.
ذات دلالــة إحصـائية بـين اسـتجابات عينـة الدراسـة على المحـورين الأول والثـاني وبـين متغيـر طبيعـة الدراسة بالكلية مما يدل على أن كل الكليات بحاجة

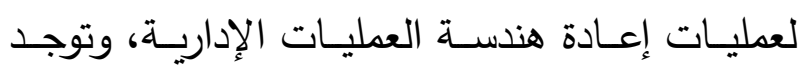
فـروق ذات دلالــة إحصـائية ضــعيفة عنـد مسـتوى (0. • • ) بين استجابات عينـة الدراسـة على إجمالي الاستبانة وبين متغير طبيعـة الكليـة لصـالح الكليات العلمية مما يدل على أن الكليات العلمية أكثر شعورا قلـيلا مـن الكليـات ذات الطبيعــة النظريــة بأهميــة

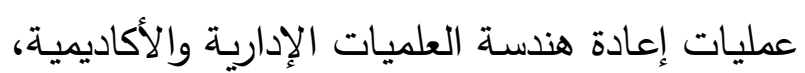
ربما يرجع ذلك لما تطلبه تلك الكليات من تجهيزات

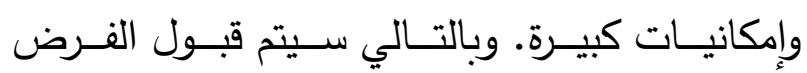
الصفري. ثالثا: فيما يتعلق بالإجابة على الأسئلة المفتوحة: وجاءت الإجابة عنها كما يلي: • سعي الجامعه لعمل حرالك علمي مع الجامعات السعودية في جميع التخصصت عن طريق استقطاب فئات من ذوي الخيرات لعمل دورات وسيمنارات في التخصصات المختلفة، واقترح عمل مراكز بحثية وتطوير المعامل المركزية، وتطوير البنية التحتية للجامعة، وتشجيع الاعضاء على البحث العلمي، ورفع مستوى الدعم للجوانب التقنية، وتخصيص التص ميزانية أكبر للبحث العلمي، ودعم الابحاث العلمية بشكل أكبر، وتفعيل المشاركة المجتمعية بشكل حقيقي. 
رؤية ورسالة الجامعة على موقع الجامعة، والخطة

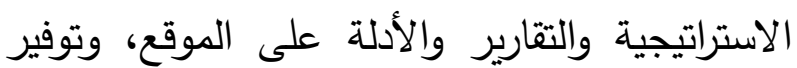

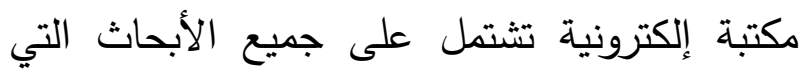
يقدمها الجامعة، وكذلك مكتبة برامج تشتمل على البرامج الهامة لهم كبرنامج ال SPSS السرقات العلمية، وقاعدة بيانات لأعضاء هيئة

التدريس ورابط للتقييم. خذمـة المجتمع والعلاقـات الدوليـة: خدمـة تعليم

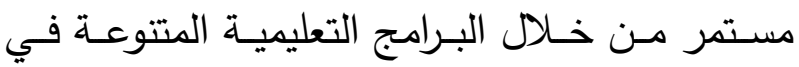
مجالاتها ومفاهيمها وطرق تقديمها، وإطلاق مبادرات

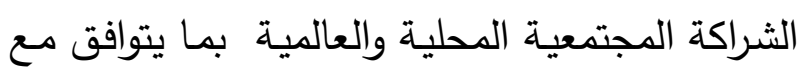

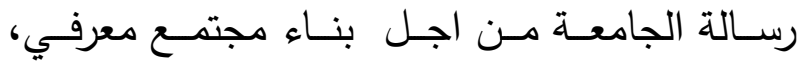

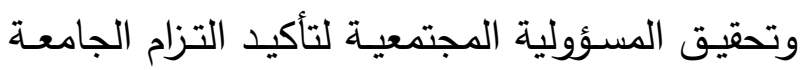
برسالتها في خدمة وتتمية المجتمع.

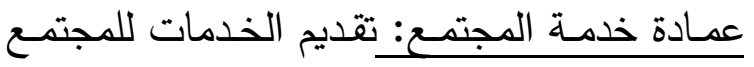
المحيط في صسورة مجموعـة مـن البرامج المدروسـة جيدا لخدمة الافراد والجماعات سواء لحل مشـاكلهم او للدعمه او للرقي، وتحفيز العاملين بالمؤسسـات الجامعيـة على العطـاء والبذل والإبـداع، والتخطيط الجيــ لمجموعـة البرامج التي تقدمها عمـادة خدمـة

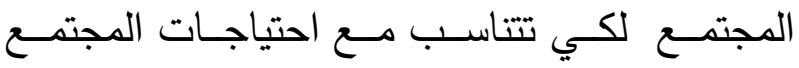
والبحث عن شراكات مجتمعية حديثة ومتنوعة سواء على المستوي المحلـي او العـالمي بمـا يسـاهم في تطـوير المجتمع المحيط، وعقد الجامعـة اتفاقيـات تعاون وشراكة مع الجامعات المتقدمة عالميا ومراكز

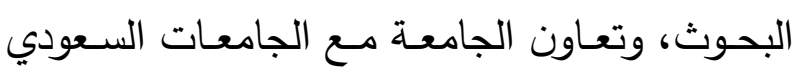

تتمية القدرات: رفع كفاءة وحدة تتمية قدرات أعضاء هيئة التدريس بالجامعة، وتلبية احتياجات أعضاء هيئة التدريس الدورية من الدورات التدريبية التي يحتاجونها بشكل سريع، وعمل سيمينار دوري معلن عنه يحضره أحد كبار المتخصصين لإلقاء ونئ محاضرة عن الجديد في كل تخصص وتقييمها، وعمل مؤتمر سنوي يحضره كبار المتخصصين في مجال التربية ويقومون بناقشة ما تم التوصل إليه من نتائج بحثية تخص الجامعة بالإضافة للأبحاث الأخرى المقدمة دن الخارج. • المناخ التظيمي: عمل توصيف مهام لجميع منسوبي الجامعة وتسليمه إليهم. والمرونة وسعة الصدر في التعامل، وتشجيع القيادات الإدارية و الفنية على العمل بروح الفريق و التعاون، والاستجابة

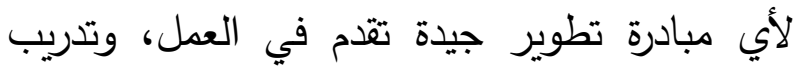
صف ثاني من القايادات حتى يسير العمل في غياب المدير بكفاءة لتفويضه مهامه لنائبه في حالة غيابه، والإعلان عن القرارات الهامة التي تتخذها الإدارة العليا، ومشاركة الجميع في وضع الخطط الاستراتيجية للجامعة، ومشاركة الجميع في تتفيذ الخطة الإستراتيجية للجامعة ووضع الخطط التنفيذية

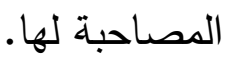

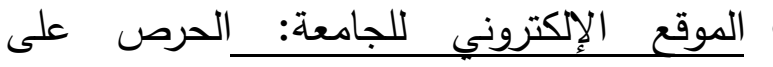
التحديث المستمر للموقع الإلكتروني للجامعة باللغتين العربية والانجليزية، نشر جميع القرارات واللوائح والقوانين المنظمة للجامعة على الموقع، نشر 
النشيط مع المحتوى والزملاء والمعلم بشكل متزامن او غير متزامن في اي وقت واي مكان بحيث يناسب ظروف المتعلم وقدرته ومنها اساليب التعليم الالكتروني، والاهتمام بعملية رقمنه التعليم وتحديثها

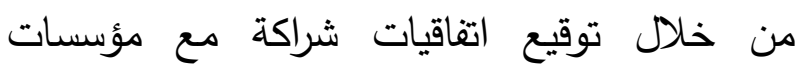
تكنولوجيا المعلومات المتطورة • التقوبم: عمل استطلاع رأي أعضاء هيئة التدريس في الخدمات المقدمة لهم لتطويرها، وخدمات المكتبة، والهيئة الإدارية، والنظافة، وأداء رؤساء العمل. وعمل استطلاع رأي للطلاب لقياس مدى ولى ولئه رضاهم عن أداء أعضاء هيئة التدريس، الخدمات الهقدمة لهم لتطويرها، وخدمات المكتبة، والهيئة الإدارية، والنظافة.

ثانيا: المحور الثاني: متطلبات إعادة هندسة العملية الأكاديمية: أولا: التدريس والتعليم:

ويشمل الانتقال من ادارة الامتحانات التحريرية كوسيلة وحيدة للتقويم تقيس مخرجات التعلم في جانب واحد من جوانب التعلم هو المعرفي الى أدارة طرق ووسائل التقويم المختلفة التي تقيس مخرجات التعلم في كافة جوانب التعلم، ودعم تتمية الأبداع من

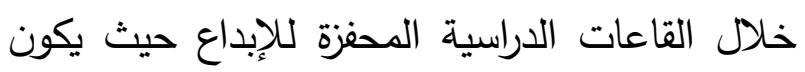
دور الطلاب فيها أنتاج المعرفة كل حسب قدراته ومواهبه ويكون دور اعضاء هيئة التدريس اكتثاف دون وتوجيه ودعم إبداعات الطلاب، والتركيز على دور الجامعة كمركز إشعاع حضاري لله دورفي احداث
الأخرى لخدمـة المجتمعـ، وإرسـال الجامعـة أعضـاء هيئة تدريس في مهام علمية وبعثات للدول المتقدمة للاستفادة من خبراتهم، وتقديم الجامعة خدمة تحديد العينـات الصـحيحة للأبحـاث والتحليـل الإحصـائي المناسـب لهـا للبـاحثين مـن خـارج الجامعـة، وتقديم

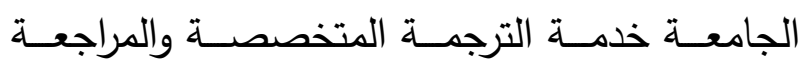
اللغوية والنشر الدولي للباحثين من خارج الجامعة. هندرة عمادة القبول والتسجيل: التركيز على توفير برامج احصائية متقدمة ومتنوعة تساعد في سرعة ودقة انجاز عمليات العمادة، وتوفير الاتصال بكافة وحدات واجهزة العمادة الداخلية وكذلك كافة كليات

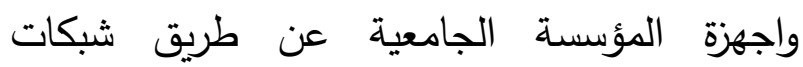
اتصالات داخلية توفر قاعدة بيانات لجميع الوحدات تساعد على سرعة ودقة الحصول على البيانات مما يساعد على انسيابية وتتاغم الأداء وسرعة اتخاذ على على التهات القرارات وعدم تضاربها. وتطبيق اللامركزية في أدارة عمادة القبول والتسجيل حيث يتم اتخاذ القرار حيثما تطلب الامر ذلك دون الاتجاه إلى اخذ موافقة

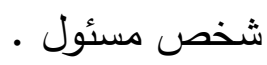
هندرة عمادة تقنية المعلومات: - ضرورة الحفاظ على تحقيق الاتصال الدائم بالطلاب والمجتمع المحيط مع القدرة على تأمين احتياجات الطلاب، ودعم دور المؤسسة الجامعية كمركز إشعاع حضاري يدير ويوجه التغيير في البيئة المحيطة، ودعم استخدام تقنية المعلومات المطورة في تطبيق اساليب التعليم الحديثة التي تتيح للطالب التفاعل 
التدريس على كيفيـة استخدام الوسـائط التكنولوجيـة الموجودة بالقاعات، وتوفير دعم فني جيد للقاعات الماته لإصلاح أي عطل يطرأ داخل القاعات. ثانيا: تصميم المناهج: - إن • عمل مواصفات المقررات ملائمة للتطورات

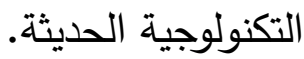
تصميم مقررات تفاعلية على موقع الجامعة لكل مقرر تدريسي. عمل حقائب تكنولوجية إلكترونية لكل مقرر للمسجلين بالمقرر من بعد.

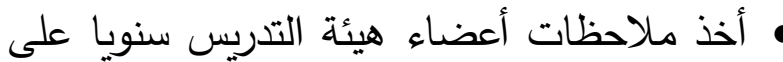

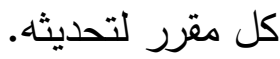
• أخذ ملاحظات الطلاب سنويا على كل مقرر

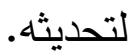

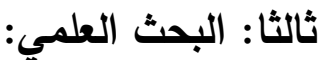
توفير خطة بحثية محددة ومعلنة للجميع تتناسب مع طبيعة المؤسسة ورسالتها توفير وحدة تحليل إحصائي تقوم بالاختيار الصحيح لعينة البحث الممثلة للأصل الكلي والتحليل

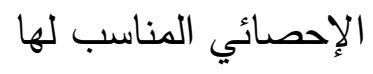

• تخصيص الجامعة ميزانية كافية تمكنها من تحقيق خطتها البحثية، وعمل تحكيم للأبحاث العلمية من خبراء في التخصص خارج الجامعة بعد الانتهاء منها، وعمل سياسات لحماية حقوق الملكية الفكرية، ونشر الأبحاث التي يقدمها الجامعة في مجلة علمية

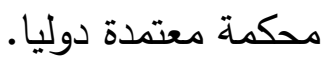

التغيير في البيئة المحيطة به عن طريق توجيه البرامج التعليمية لكل ما يخدم المجتمع المحيط، بله والتتظيم على اساس مخرجات التعلم وليس على لئ المهام التي يقوم بها العاملون بالمؤسسة الجامعية. كفاءة الطلاب: وتثمل تقليل نسب الرسوب سنويا، والقضاء على التسرب من الجامعة، ورفع المعدلات

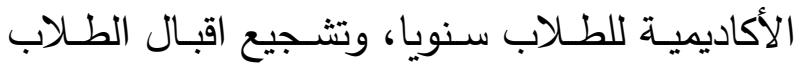
على استكمال دراستهم العليا بشكل كبير ، وتشجيع الطـلاب على التردد كثيـرا على المكتبـات لإنجـاز

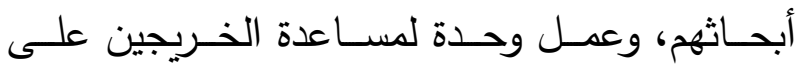
الالتحاق بسوق العمل بعد تخرجهم ومتابعتهم. كفــاءة أعضــاء هيئــة التـــريس: وتشــل مراعـاة التخصـص العلمـي في تـدريس البـرامج الأكاديميـة بشكل دقيق، وربط استمرارية أعضاء هيئة التدريس بالجامعـة بعمل بحث واحـد على الأقل سـويا في لهي مجال تخصصهم لمواكبة الجديد، وتوفير آلية لعمل

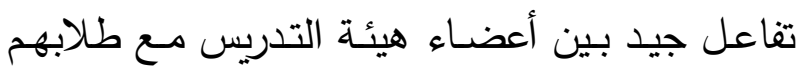

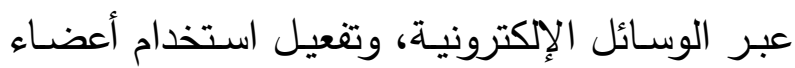

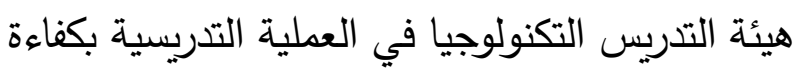
عالية. - مالية التكنولوجيا في حجرة الاراسـة وتثمل توفير قاعات تدريسية مزودة بأجهزة عرض مناسبة، وتوفير انترنت موصل بالقاعـات التدريسية لاستخدامة في العملية التدريسية، وتوفير سبورات ذكية بالقاعات التدريسية،

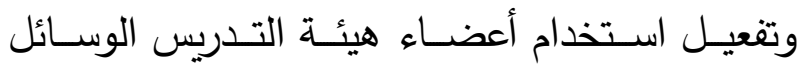
التكنولوجيـة أثنـاء التـدريس، وتدريب أعضـاء هيئة 
معلم العصر الرقمي. الرياض: جامعة الأميرة نورة

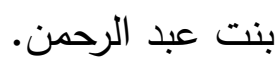

0- البرزنجي، آمال كمال حسن، عبد الرضا، علوان نوفل (2006)، بناء وتطبيق نموذج لإدارة الجودة الثاملة لنهوض بالمؤسسات التعليمية في العراق، دراسة تطبيقية، مجلة الادرة والاقتصاد، جامعة الموصل، العدد إن. 7عبد الحميد (0بـ ()، المرجع الحديث في الهندسة الادرارية ، جدة ص 1• 1.

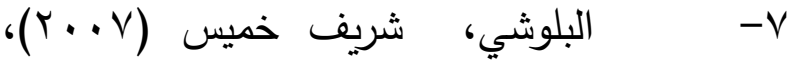
اعادة هندسة العمليات الادارية وامكانية تطبيق متطلباتها في كليات التربية بسلطنة عمان، رسالة ماجستير ، كلية التربية، جامعة السلطان قابوس .

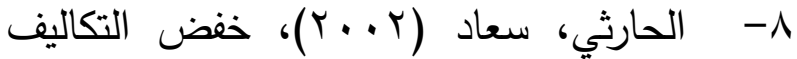
في مؤسسات التعليم العالي باتباع اسلوب هندسة العمليات الادارية كليات جامعة البنات في المملكة العرية السعودية نموذجاً"، رسالة دكتوراه، كلية الدراسات العليا، جامعة نايف العربية للعلوم الامنية

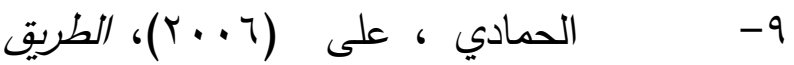
إلى التصيز 10 طريقة للتغيير ، دار ابن حزم

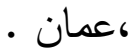

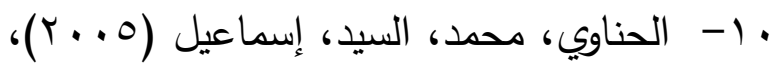
قضايا إدارية معاصرة ، الدار الجامعية، الإسكندرية الدية إنياعيل .
توفير ميزانية كافية لتمويل البرامج وقواعد البيانات والأجهزة الضرورية لإجراء البحث العلمي وذلك في جميع الثعب، وعمل آلية للتطوير المستمر لخدمات المكتبة بما يدعم احتياجات التدريس والبحث

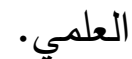
توفير قواعد بيانات إلكترونية تثتمل على المراجع والمجلات العلمية التي تقدمها الجامعة سهل الوصول إليها، وعمل وحدة ترجمة متخصصة

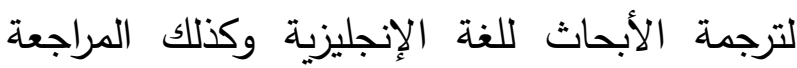
اللغوية، ووحدة النشر الدولي.

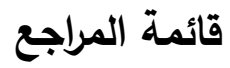

أولاً: المراجع العربية:-

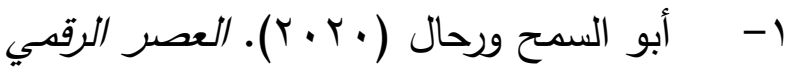
والتعليم. موقع تكنولوجيا التعليم. تم الاسترجاع في

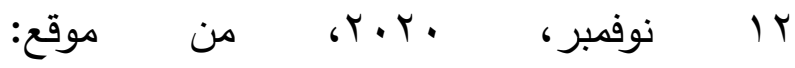

(http://www.khayma.com/educationtechnology/Study24.htm)

r- أبو شنب، جمال (999 (1)، العلم والتكنولوجيا من البداية وحتى الآن، دار المعرفة

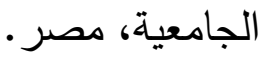

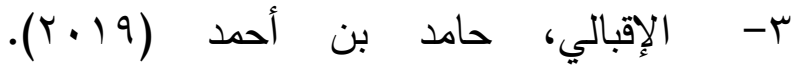
مقتضيات التحوّل إلى التعلم الرقمي الموجّه لصغار

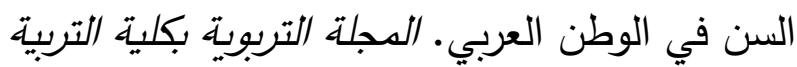
جامعة سوهاج. (77) (7).

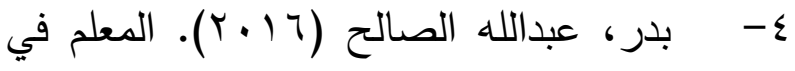
عصر المعرفة الرقمي: تحديات وتحولات. ملتقى لـ 
11- سيلفا، باولا ألكساندرا (1/ • Y). التعليم في العصر الرقمي: آفاق من تجربة شخصية. في: الاتحاد الدولي للاتصالات (1) • ب). بناء القدرات في بيئة متغيرة لتكنولوجيا الدعلومات والاتصالات. جنيف. V-V

9 19- الثمري، ثاني حسين (19 (ب). دور التعلم الرقمي في التنمية المهنية للمعلمين. المجلة العربية

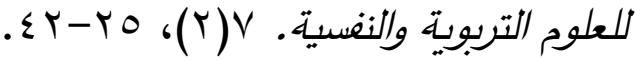

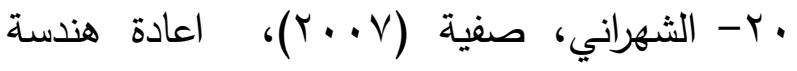
اساليب التعليم الجامعي لمواجهة متطلبات عصر

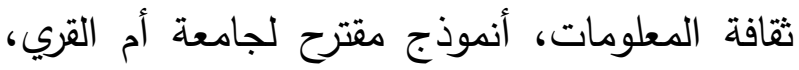
رسالة دكتوراه، مكة المكرمة، المملكة العربية

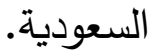

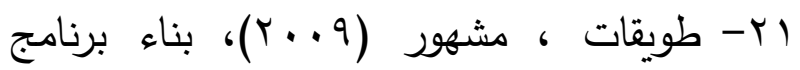
تدريبي مقترح لتطوير المهارات القيادية المبدعة

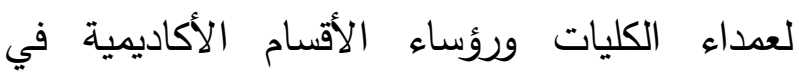
الجامعات الاردنية في ضوء الاتجاهات الادارية

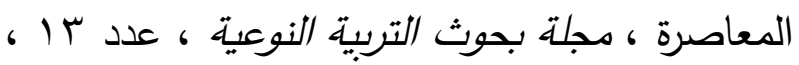
$.110-10 \mathrm{~V}$

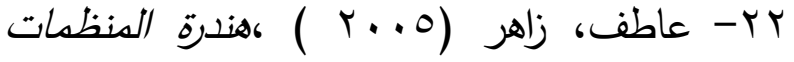

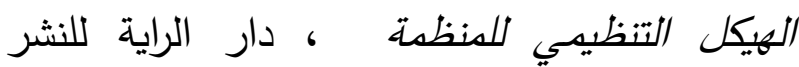

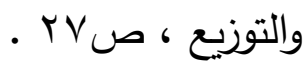

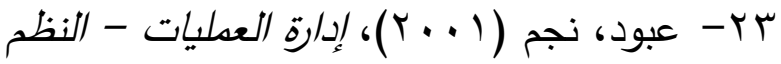
والأساليب والاتجاهات الحديثة"، مركز البحوث، لإن،

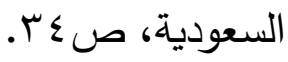

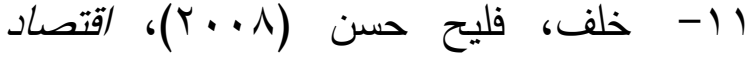
المعرفة، عالم الكتب الحديث، الأردن.

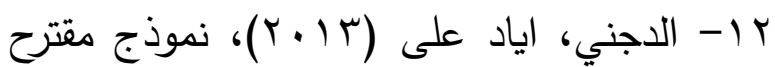
لإعادة هندسة العمليات الإدارية وحوسبتها في العي مؤسسات التعليم العالي (الجامعة الإسلامية دراسة حالة)، كلية التربية، جامعة دمشق.

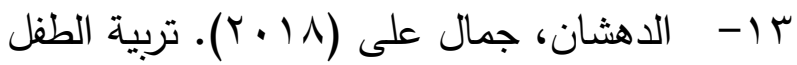
المصري في العصر الرقمي بين تحديات الواقع وطموحات المستقبل، ورقة عمل مقدمة إلى المؤتمر الدولي الأول لكلية رياض الأطفال جامعة أسيوط

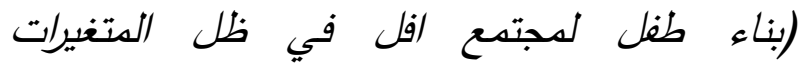

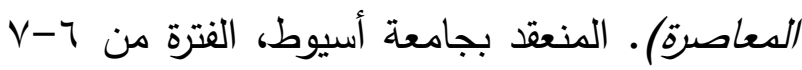

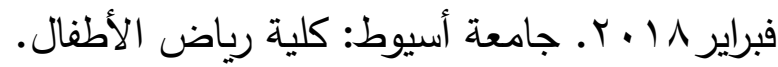
ـ ا- ديسلر، جاري ( 2003 )، ترجمة د .محمد

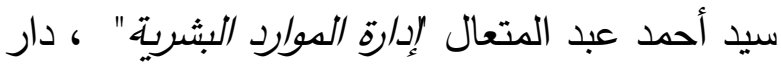
· المريخ للنشر

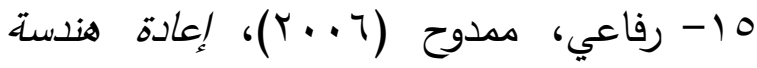
العمليات ، القاهرة، جامعة عين شمس، ص13.

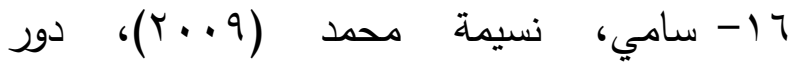
تكنولوجيا المعلومات في تسويق الخدمات المصرفية، دراسة حالة واقع المصرف التجاري السوري، مذكرة ماجستير في ادارة الاعمال، كلية الاقتصاد، جامعة العائ

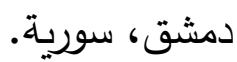

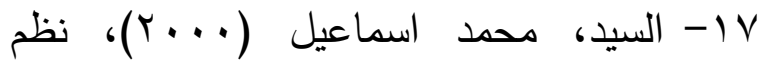
المعلومات لاتخاذ القرارات الإدارية، المكتب العربي الحديث، الإسكندرية، مصر • 


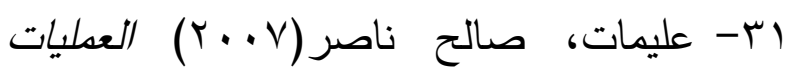
الادرية في المؤسسات التربوية، دار الثروق للنشر • عمان

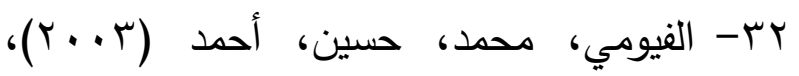
تصديم وتشغيل نظم المعلومات، كلية التجارة، جامعة الاسكندرية، الاسكندرية، مصر •

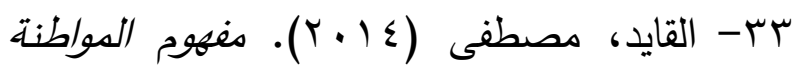
الرقمية. المركز العربي لأبحاث الفضاء الإلكتروني.

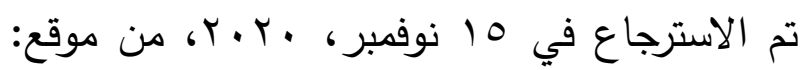

http://www.accronline.com/article_detai . (l.aspx?id=19035 ع ب- القريوتي، محمد (2000) ، السلوك التنظيمي دراسة السلوك الإنساني الفردي والجماعي في المنظمات المختلفة، عمان، دار الثروق للنشر • $343 ،$ والتوزنيع

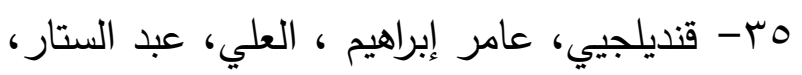

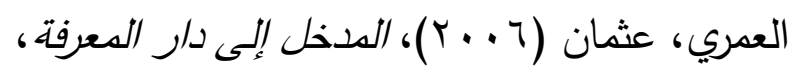
دار المسيرة للنشر والتوزيع والطباعة، عمان،

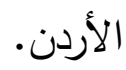

جس- قنديلجيي، عامر إبراهيم ،السامرائي، إيمان فاضل (Y . . Y)، تكنولوجيا المعلومات وتطبيقاتها، الوراق للنشر والتوزيع، عمان، الأردن.

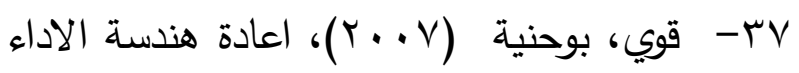
الجامعي ، مقارنة معاصرة، مجلة الباحث ، العدد
צ ז- عسلة، عزة محمد (19 (r). تصور مقترح للتندية المهنية الإككترونية للمعلدين في ضوء تحديات العصر الرقهي. رسالة ماجستير · جامعة المنوفية: كلية التربية.

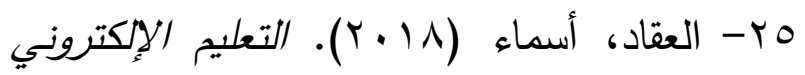
والتحديات المعاصرة. ورقة عمل مقدمة: للمبورد الذهبي العالمي للتدريب والاستشارات. فلسطين: جامعة بيرزيت - كلية تكنولوجيا المعلومات. فبراير • דr- عقيلي، عمر وصفي، (1 (. (Y)، مدخل إلى المنهجية المتكاملة لإدارة الجودة الثاملة ، دار وايل ل للنشر ، عمان، ص 90. (YV الرقمي: الطموحات والتحديات. المجلة التربوية.

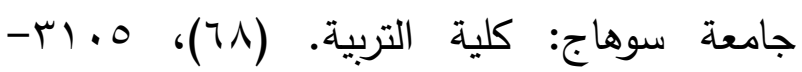
.TI

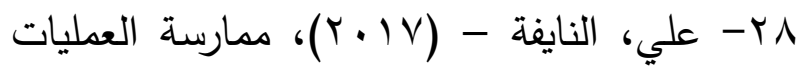
الإدارية في جامعة تشرين وفق مدخل هندسة العمليات الادارية من وجهة نظر اعضاء الهيئة التعليمية والادارية في الجامعة ، مجلة اتحاد الجامعات العربية للتربية وعلم النغس، 0 (ب). وץ- علي، نبيل (999). العرب وعصر

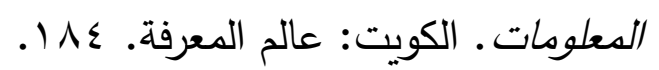

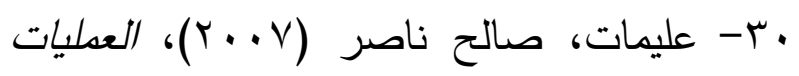
الإدارية في المؤسات التربوبية، القاهرة، دار الشروق للنشر والتوزيع. 
؟ §- هامر، مايكل، وشامبي، جيمس (199 (1)،

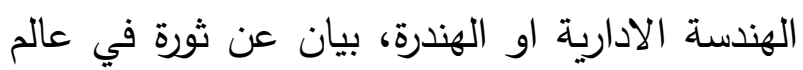

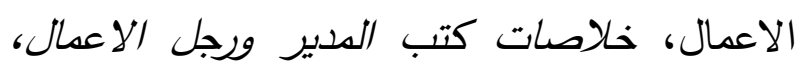
(r. ( ) ، الثركة العربية للإعلام العلمي( شعاع)، القاهرة.

؟ - هامر، مايكل، وشامبي، جيمس (1990 (1)،

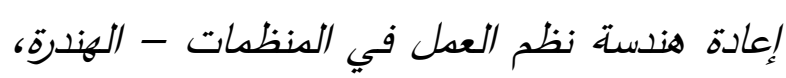

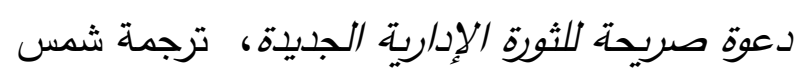

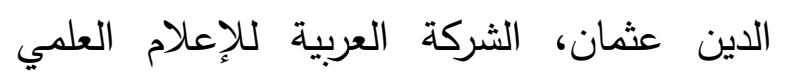

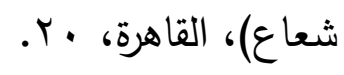

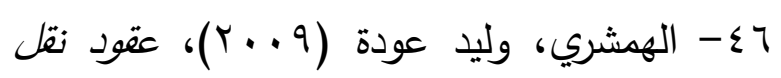
التكنولوجيا، دار الثقافة للنشر والتوزيع، عمان،

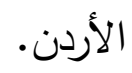

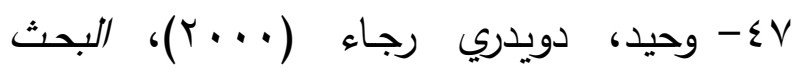

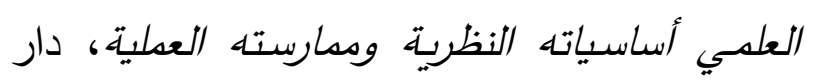
الفكر المعاصر ، سورية.

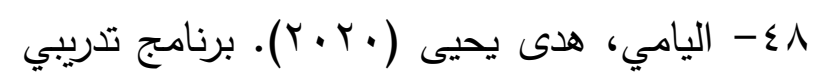

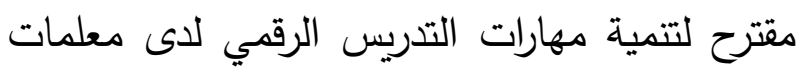

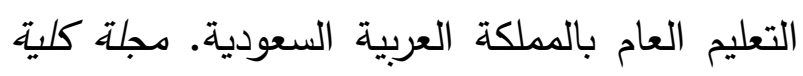

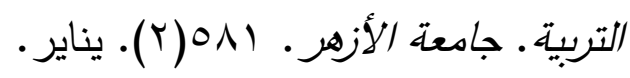

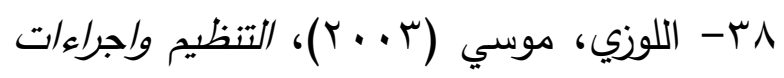
العمل، دار وايل للنشر ، عمان.

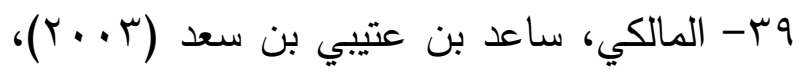

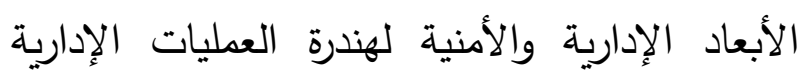
وعلاقتها بالأداء الوظيفي دراسة ميدانية على وكالة الإدية الآثار والمتاحف بالمملكة العربية السعودية، رسالة

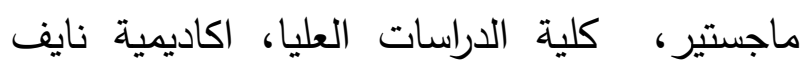

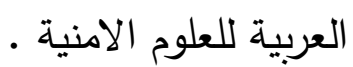

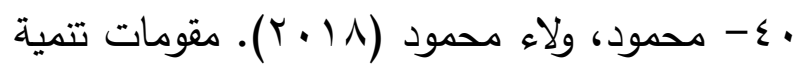
الموارد البشرية الأكاديمية بجامعة بنها في العصر الرقمي "الواقع وسيناريوهات المستقبل. مجلة كلية

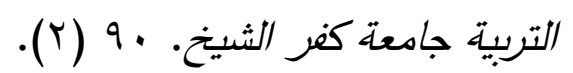

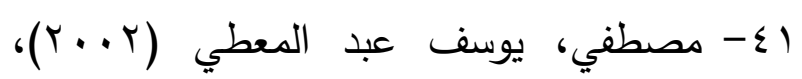
أنموذج مقترح للتطبيق مفهوم اعادة هندسة العمليات في التعليم الجامعي، مجلة التربية، ه ( (†).

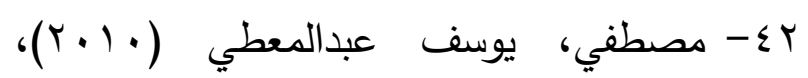
الإدارة التربوية -مداخل جديدة ...لعالم جديد، دار الفكر العربي، ط سب، القاهرة.

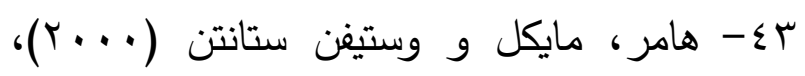

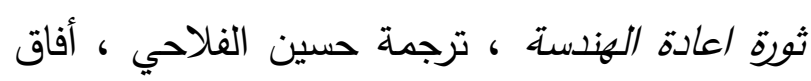

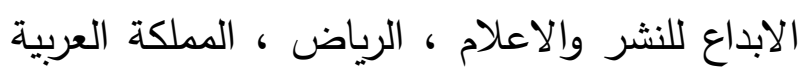
السعودية . الابل 


\section{ثانيا : المراجع الاجنبية:}

1. Abdous, M. \& He, W. (2008), A Frame Work for Process Reengineering in Higher Education", A case study of distance learning exam scheduling and distribution, The International Review of Research in Open and Distance Learning,9(3).

2. Ale (2017). Active Learning in Engineering Education, Accessed on 24/02/2017, Available at: http://www.alenet.org/ .

3. Ali, A. (2016, November). Re Engineering of Training to Success. In Abu Dhabi International Petroleum Exhibition \& Conference. Society of Petroleum Engineers.

4. Allen, D.K. \& Fifield, N. (1999), Reengineering change in higher education, Information Research, 4(3), U.K,February. http://informationr.net/ir/43/paper56.html.

5. Brooks ; D. Christopher and McCormack.; Mark (2019). Higher Education's 2019 Trend Watch and Top 10 Strategic Technologies. Research report. Louisville, CO: ECAR, March 2019.

6. Catalano, Horaţiu (2019). Opportunities and Challenges of Education in the Digital Age. Astra Salvensis-revista de istorie si cultura. 7(14), 25-30.

7. Celis, S. (2016). Redesigning Engineering Education in Chile: How Selective Institutions Re-spond to an Ambitious National Reform. ASEE's $123^{\text {rd }}$ Annual Conference \& Expositions, New Orleans,
LA, June 26-29, 2016, American Society for Engineering Education.

8. Chagas, M., Gomes, R., Bermejo, P. H., \& Martins, J. (2017, August). Institutionalization of the Reengineering of Strategic Management Processes in the Brazilian Public Management: A Case Study in Federal Government Organizations. In International Conference on Electronic Government and the Information Systems Perspective (pp. 221-235). Springer, Cham.

9. Chain, K. K. \& Spedding, T. (2003), An integrated multidimensional process improvement methodology for manufacturing system, Computers \& Industrial Engineering ,44(4), 673- 693 .

10. Christie, M., \& de Graaff, E. (2017). The philosophical and pedagogical underpinnings of Active Learning in Engineering Education. European Journal of Engineering Education, 42(1), 5-16.

11. David, Raluca, et al. (2020). Education During the Covid-19 Crisis: Opportunities and Constraint of Using EdTech in Lowincome Countries. The EdTech Hub \& Digital Pathways at Oxford. April.

12. Doyle, Lee (2004). "Business Process Reengineering (BPR): A Tool for Improved Customer Service in Municipalities". MPA Major Research Papers. $\quad 47$. http://ir.lib.uwo.ca/lgpmrps/47

13. Doyle, Lee (2004). "Business Process Reengineering (BPR): A Tool for Improved Customer Service in Municipalities". MPA Major Research Papers. $\quad 47$. http://ir.lib.uwo.ca/lgpmrps/47

14. Dussault, Adrien (2018). 2018's Top 8 Classroom Challenges, According to Teachers. Classcraft Studios Inc. 4 June.

15. Fragoso, J. T. (2015). Business Process Reengineering in Government Agencies: 
Lessons from an Experience in Mexico. Journal of Service Science and Management, 8(03), 382-392.

16. Francis, Ahmad \& Zairi, Mohhamed (2007), Business process reengineering critical success factors in higher education, Business Process Management Journal, Bradford, 13(3) .

17. Giraffa, L. M. \& Marczak, Sabrina (2012). Being a Digital Teacher: Myths, Dilemma and Challenges for $21^{\text {st }}$ Century Teachers. 4th International Conference on Education and New Learning Technologies. Spain. 2-4 July, 2267-2273.

18. Haris, Adnan (2016). Information Issues in Digital Era. Malysia: Faculty of Information Management.

19. Jha M., Jha S., O'Brien L. (2019) Reengineering Higher Education Learning and Teaching Business Processes for Big Data Analytics. In: Abramowicz W., Corchuelo R. (eds) Business Information Systems. BIS 2019. Lecture Notes in Business Information Processing, vol 354. Springer, Cham.

20. Lo, W. S. (2017). ORGANIZATIONAL INNOVATION INTO PROCESS REENGINEERING: A CASE STUDY OF A PRACTICAL TRAINING HOTEL. International Journal of Organizational Innovation (Online), 9(3), 63.

21. Meilleur, Catherine (2018). 4 Challenges for Education in the Digital Revolution Era. Canada: knowledgeone. Retrieved Oct. $\quad 3, \quad 2020, \quad$ from: https://knowledgeone.ca/4-challenges-foreducation-in- the-digital-revolution-era.

22. Mekonnen, N. (2017). Implementing Business Process Reengineering (BPR) in Government Organization. Available at SSRN: https://ssrn.com , Accessed on 24/02/2017.

23. Novak, J., Farr-Wharton, B., Brunetto, Y., Shacklock, K., \& Brown, K. (2017).
Safety outcomes for engineering asset management organizations: Old problem with new solutions? Reliability Engineering \& System Safety, 160, 67-73.

24. Omidi, A., \& Khoshtinat, B. (2016). Factors Affecting the Implementation of Business Process Reengineering: Taking into Account the Moderating Role of Organizational Culture (Case Study: Iran Air). Procedia Economics and Finance, 36, 425-432.

25. Parker, J., (1993), "An ABC Guide to Business Process Reengineering", Industrial Engineering, May.

26. Paul, A. \& Cespedes, S., (1995), "Reengineering is Just Acatalyst in Bank Culture Change", The Bankers Magazine, May-June.

27. Rossikhina, H., Rossikhin, V., \& Kaganovska, T. (2019, December). Problems of Education Digitization in Ukraine. In: International Scientific and Practical Conference on Digital Economy (ISCDE 2019). Atlantis Press.

28. Rottmann, C., Reeve, D. W., Sacks, R., \& Klassen, M. (2017). An Intersubjective Analysis of Engineering Leadership Across Organizational Locations: Implications for Higher Education. Canadian Journal of Higher Education, 46(4), 146-173.

29. SALLEH, KAHIROL

SULAIMAN, NOR MOHD\& BUSINESS LISA(2012)

REENGINEERING PROCESS

MALAYSIANHIGHER EDUCATION INSTITUTIONS, International Journal of Business Management \&Research, 2 (3), http://www.academia.edu/4035286/Busine ss_Process_Reengineering_in_Malaysia Higher_Learning_Institutions_IJBMR_Ka hirol_Mohd_Salleh

30. Sharma, Manisha (2017). Teacher in a Digital Era. Global Journal of Computer 
Science and Technology. USA: Global Journals Inc. 17(3).

31. Slåtto, T., Buhl, M., Larjanko, , J., Ossiannilsson, E., Gjelsvik, T., \& Huttula, T. (2020). Learning for everyone in a digital society, . ISO 690 , Available at: https://vbn.aau.dk/ws/portalfiles/portal/32 2220634/Report_learning_digital_society 200220_final.pdf , Accessed on:29/12/2020.
32. Sprawls , Perry (2013). "Re-engineering the Educational Process". Apeejay Stya Education Research Foundation, June 2013, [online] Available: http://www.sprawls.org/RE/ , 17/12/2016.

33. Towner, W. (2017). Reengineering engineering education. IEEE Engineering Management Review, 45(2), 34-36. 


\title{
"Requirements for applying the Re-engineering of Saudi universities in light of the challenges of the digital age"
}

\author{
Dr. thahab Naif Elshammary \\ Associate Professor of Educational Administration \\ Department of Education - College of Education - University of Hail
}

\begin{abstract}
Saudi universities in light of the challenges of the digital age, and in this study was limited to the University of Hail as a model given that it is the university in which the researcher works and is the most familiar with it, and the study used the descriptive approach, and the questionnaire tool was used to find out the availability of the requirements for the application of engineering In universities, in preparation for developing a number of recommendations to support the available requirements, and to provide for the unavailable requirements, the questionnaire was applied to faculty members at the University of Hail in a number of theoretical and practical colleges in the male and female sections.

The results of the study resulted in a relatively superior axis of requirements for re-engineering of academic processes over the axis of requirements for re-engineering of administrative processes. The first reached (59.89\%), while the second reached $(57.07 \%)$, which indicates that the academic operations of the university are better than the administrative operations.

The study ended with the development of a number of recommendations that would support the available engineering requirements and provide for the unavailable engineering requirements on the administrative and academic axes.

Key words:

Reengineering - the digital age - Saudi universities
\end{abstract}

